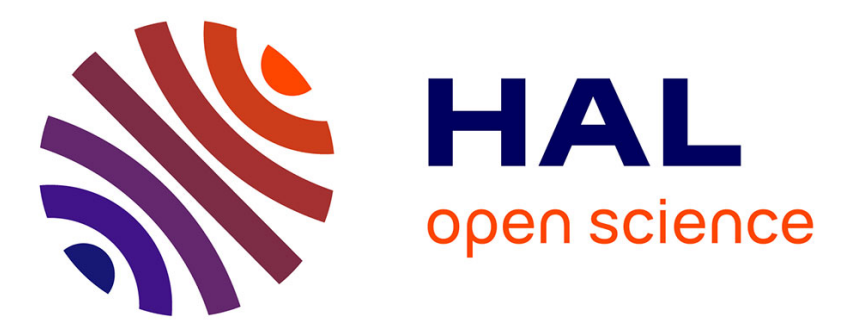

\title{
Insights in aroma compound retention by mucosa during consumption through mathematical modelling
}

\author{
Isabelle Deleris, Anne Saint-Eve, Aurélie Saglio, Isabelle Souchon,
}

Ioan-Cristian Trelea

\section{- To cite this version:}

Isabelle Deleris, Anne Saint-Eve, Aurélie Saglio, Isabelle Souchon, Ioan-Cristian Trelea. Insights in aroma compound retention by mucosa during consumption through mathematical modelling. Journal of Food Engineering, 2016, 190, pp.123-138. 10.1016/j.jfoodeng.2016.06.018 . hal-01532599

\section{HAL Id: hal-01532599 \\ https://hal.science/hal-01532599}

Submitted on 11 Jul 2017

HAL is a multi-disciplinary open access archive for the deposit and dissemination of scientific research documents, whether they are published or not. The documents may come from teaching and research institutions in France or abroad, or from public or private research centers.
L'archive ouverte pluridisciplinaire HAL, est destinée au dépôt et à la diffusion de documents scientifiques de niveau recherche, publiés ou non, émanant des établissements d'enseignement et de recherche français ou étrangers, des laboratoires publics ou privés. 
1 INSIGHTS IN AROMA COMPOUND RETENTION BY MUCOSA DURING

2 CONSUMPTION THROUGH MATHEMATICAL MODELLING

3 Isabelle Déléris, Anne Saint-Eve, Aurélie Saglio, Isabelle Souchon, Ioan Cristian Trelea

4 UMR 782 GMPA, AgroParisTech, INRA, Université Paris-Saclay, 78850, Thiverval-

5 Grignon, France

6 isabelle.deleris@grignon.inra.fr; seanne@grignon.inra.fr; isabelle.souchon@grignon.inra.fr;

$7 \quad$ cristian.trelea@agroparistech.fr

8 Correspondence to be sent to: Isabelle Déléris, UMR 782 Génie et Microbiologie des

9 Procédés Alimentaires, 1 avenue Lucien Brétigniéres, F-78850 Thiverval-Grignon, France.

10 email: $\underline{\text { isabelle.deleris@grignon.inra.fr }}$ 


\section{Highlights}

- Aroma compound persistence after gaseous sample inhalation was modelled.

- Both physiological and physicochemical parameters were included in the model.

- The respective contributions of wetted mucosa and saliva on release kinetics were assessed.

- The major role of mucosa partition coefficients of molecules was confirmed. 
11 Abstract

12 A multidisciplinary approach combining physiology and physical chemistry and associating experimental measurements with in silico modelling was applied to explain the release of aroma compounds during food consumption. Experimental release kinetics obtained by inhaling gaseous samples through controlled protocols highlighted different release behaviours, depending on aroma compound properties. The associated mathematical model described mass transfer mechanisms between the different compartments of the naso-oropharyngeal cavities and included both physicochemical and physiological parameters. One of the main developments was notably to consider the possible retention of aroma compounds by wetted mucosa. Model sensitivity analysis confirmed the key role of interaction between aroma compounds and mucosa (air/mucosa partition coefficient) and of individual breath parameters (current breath volume and respiratory frequency) on the persistence of aroma compound in exhaled air. These achievements show that the association of an experimental approach and mechanistic modelling constitutes a powerful tool to improve the understanding of aroma release and persistence.

Keywords: aroma release, wetted mucosa, saliva, persistence, interaction, dynamic modelling

\section{Chemical compounds studied in this article:}

ol (PubChem CID: 10993), polypropylene glycol (PubChem CID: 1030).

30 Short running title: Modelling of in vivo aroma retention

\section{$31 \quad$ Highlights}

32 - Aroma compound persistence after gaseous sample inhalation was modelled.

33 - Both physiological and physicochemical parameters were included in the model.

34 - The respective contributions of wetted mucosa and saliva on release kinetics were assessed.

35 - The major role of mucosa partition coefficients of molecules was confirmed. 


\section{Introduction}

Olfactory perception is known to largely contribute to overall perception of foods and, consequently, to consumer choice and preferences. A better understanding of this specific perception is therefore of great importance and requires the identification of the main mechanisms at the origin of aroma compound release during food consumption. Several studies have notably focused on orthonasal and retronasal perceptions to highlight the origin of the main differences between these two perception pathways (Espinosa Diaz, 2004; Halpern, 2004; Heilman and Hummel, 2004; Hummel, 2008; Hummel et al., 2006; Sun and Halpern, 2005; Visschers et al., 2006; Welge-Lüssen et al., 2009). The large number and the variety of mechanisms (physical, chemical, physiological, neurobiological, cognitive, etc.) that can be involved at different space and time scales largely contribute to the complexity of perception. Among them, the release dynamics of aroma compounds have long been known to be among key factors to explain aromatic perceptions (Barron et al., 2012; Biasioli et al., 2006; Déléris et al., 2011; Gierczynski et al., 2011; Heenan et al., 2009). Numerous studies in the literature have focused on the identification of the main factors that can impact release kinetics, either related to the physicochemical properties of the molecules, to product characteristics (composition, structure), to individual physiology (saliva composition and flow rate, breath flow rate) or to oral processing (chewing efficiency, product coating, etc.) (Benjamin et al., 2012; Buettner and Beauchamp, 2010; Foster et al., 2011; Frank et al., 2012; Gierczynski et al., 2011; Heath, 2002; Heenan et al., 2011). The existence of aroma compound retention by wetted mucosa has often been proposed to explain specific release behaviours, but little is known about the origin of this phenomenon. However, several mechanisms have been suggested in the literature: the interaction of aroma compounds with the constituents of the mucus layer (mucins, enzymes, antioxidants, ionic compounds), with saliva and/or with the mucosa tissues themselves (Buettner and Beauchamp, 2010); the role of 
61 the contact area between nasal mucus and air (Keyhani et al., 1997); the role of the physicochemical properties of aroma compounds (Ferreira et al., 2006; Tromelin et al., 2010); and the role of breath and/or salivary flow rates (Buettner and Mestres, 2005; Hodgson et al., 2004).

Performing in vivo experiments and developing appropriate experimental set-ups constitute the main difficulties involved in exploring this topic and in validating or not the assumptions. A previous study proposed various simple protocols to explore and quantify in vivo aroma release and persistence from gaseous samples, depending on the exposed physiological cavities (nose, mouth or pharynx) (Déléris et al., 2015). Results confirmed the main role of aroma compound properties and highlighted the possible occurrence of different types of mechanisms, either physical or biochemical, to explain release behaviours. The global nature of the approach and the complexity of the phenomena involved did not allow the authors to clearly identify the relative contribution of each mechanism.

The difficulty of dissociating all of the phenomena that occur during in vivo experiments generally prevents from determining the respective contribution of product properties or of consumer characteristics to aroma release. Due to these experimental issues, the modelling approach (in silico) can be a useful tool to improve the understanding. It has been largely used in the fields of pharmacokinetics and toxicology: Quantitative Structure-Activity Relationships (QSAR) (Geerts and Heyden, 2011), Physiologically-Based Pharmaco-Kinetic (PB-PK) (Corley et al., 2012; Medinsky et al., 1993; Morris, 2012) and Theoretical Passive Absorption (TPAM) (Obata et al., 2005; Takano et al., 2006) models have helped to better understand drug and toxic vapour absorption. In the field of olfaction, the QSAR approach has also been largely used to identify the main interactions between aroma compounds and olfactory receptors at the origin of perception (Anker et al., 1990; Chastrette and Rallet, 1998; Kraft et al., 2000; Rognon and Chastrette, 1994; Sanz et al., 2008). Some of these models 
clearly highlighted the need to consider absorption/solubilisation phenomena in tissues of the respiratory tract and/or in the mucus layer to correctly represent the availability of aroma compounds for olfactory receptors. It was demonstrated that the transport of odorant molecules in nasal mucosa clearly differs from the one within an aqueous layer (Kurtz et al., 2004). The main limitation of modelling approaches remains the lack of experimental data, notably concerning the air/mucosa partition or diffusion properties of aroma compounds within the mucus layer, or mucosa characteristics depending on its location (nasal, oral or pharyngeal cavity).

In food science, some mechanistic models describing volatile release have been proposed and sometimes compared to experimental in vivo data (Buffo et al., 2005; Harrison, 2000; Harrison and Hills, 1997; Hodgson et al., 2005; Normand et al., 2004; Wright and Hills, 2003). These models, based on physical, chemical and physiological parameters, led to more or less good predictions of the release kinetics of aroma compounds, but only for liquid food products. Only the models of (Wright and Hills, 2003) and (Normand et al., 2004) included a term representing possible interactions between aroma compounds and mucosa and/or salivary constituents. Even though many publications exist on molecular mechanisms that explain interactions between aroma compounds and proteins in the mucus of the nasal cavity of rats (Odorant Binding Proteins, OBPs), results cannot be directly used to explain in vivo release kinetics in humans (Borysik et al., 2010; Yabuki et al., 2011). All of these studies constitute a first step in describing the phenomena involved but do not yet provide a clear understanding. In a previous publication, a mathematical model was proposed to predict in vivo aroma release from masticated food products that considered food properties and the physiological characteristics of the individuals (Doyennette et al., 2014). Comparison between experimental and predicted kinetics highlighted the possible specific retention of one hydrophobic aroma compound by wetted mucosa and mucus in the naso-oro-pharyngeal 
111 cavities. This model thus needs to be further developed to propose a satisfactory quantitative

112 description of the retention phenomenon at the origin of aroma persistence.

113 In this context, the main goal of the present study is to better understand the mechanisms

114 underlying aroma release and persistence. The originality of the proposed approach is to

115 combine: (i) in vivo aroma release measurements (using controlled protocols to ensure aroma

116 supply by flavoured air inhalation, without the interference of any food product); with (ii) the

117 detailed mechanistic modelling of mass transfer to investigate the key mechanisms

118 responsible for the release profiles and/or retention of aroma compounds.

\section{2. Material and methods}

120 Even if this study was not performed in the field of medical research, a detailed research

121 protocol containing the relevant information in agreement with the World Medical

122 Association Declaration of Helsinki was done. Only single-use materials were used with

123 panellists. Aroma compounds were all food grade and their liquid concentrations were

124 adjusted to limit gaseous concentration and ensure panellist comfort and avoid sensory

125 saturation. Only one session (45 minutes) per week was planned for each panellist and the

126 number of samples during one session was limited to five. Samples were coded to protect the

127 privacy of panellist and the confidentiality of their personal information. Subjects were clearly

128 informed of the observational nature of this study, gave their free and informed consent and

129 received compensation for their participation.

$130 \quad$ 2.1. Aroma compounds

131 Food grade quality aroma compounds (ethyl propanoate, 2-nonanone and (Z)-3-hexen-1-ol)

132 were purchased from Sigma Aldrich (France) (Table 1).

133 They were selected since they belong to several chemical classes and present different

134 physicochemical properties and different release behaviours in terms of persistence (Déléris et

135 al., 2015). Concentrated stock solutions were prepared in polypropylene glycol (Sigma 
136 Aldrich, France) and used throughout the study. Diluted solutions were prepared

137 extemporaneously.

138 2.2. Gaseous sample preparation

139 An aroma compound mixture was used to reduce the number of experimental sessions.

140 Gaseous samples were prepared as previously described (Déléris et al., 2015). The

141 concentrations of aroma compounds in the liquid phase were high enough to be detected

142 during PTR-MS measurements, while being acceptable from a sensory point of view for the

143 panellists: $1000 \mathrm{mg} / \mathrm{kg}$ for $(Z)-3$-hexen-1-ol, $150 \mathrm{mg} / \mathrm{kg}$ for ethyl propanoate and $100 \mathrm{mg} / \mathrm{kg}$

144 for 2-nonanone.

145 Twenty-five $\mathrm{mL}$ of flavoured aqueous solution were stored at ambient temperature for 4 hours

146 before measurements in 250-mL flasks (Schott, France), closed by caps equipped with valves

147 (equilibrium establishment). To control the inhaled volume of gaseous sample (and, therefore,

148 the amount of inhaled aroma compounds) between the different assays, a specific set-up was

149 developed to prepare gaseous samples (Figure 1): a manual pump was connected to one of the

150 cap valves and used to push some fresh air into the flasks. By way of this procedure,

151 flavoured air was introduced into a balloon positioned on the other valve of the flask cap.

152 Three pump strokes were needed to prepare $200 \mathrm{~mL}$ of gaseous sample, which was considered 153 as appropriate to be inhaled by panellists in one breath. Once inflated, balloons were closed 154 with plastic pliers.

155 The study of the variation of aroma concentration within balloons during storage highlighted

156 the fact that this preparation had to be done less than $30 \mathrm{~s}$ before measurement to avoid any

157 loss of aroma compounds (not shown). Even if some interactions between aroma compounds

158 and balloon material could occur, they were assumed to always be the same and to not

159 influence the results since all conditions were controlled.

160 2.3. Panellists 
161 Eight panellists (four men and four women, 22-45 years old) were recruited for the study.

162 They were instructed not to smoke, eat, drink or use any persistent-flavoured product for at 163 least one hour before Proton Transfer Reaction-Mass Spectrometry (PTR-MS) or saliva 164 collection sessions.

165 When dealing with aroma release and food oral processing, lots of studies in literature largely

166 highlighted the key role that anatomy and physiology can have on the dynamics of 167 phenomena (Buettner and Beauchamp, 2010; Féron et al., 2014; Foster et al., 2011; Repoux et 168 al., 2012b). Some physiological measurements were thus performed on panellists who 169 participated to this study to define the range of variation of these parameters for the panel.

170 The volumes of the oral, nasal and pharyngeal cavities of the subjects were measured with the 171 Eccovision Acoustic Rhinopharyngometer (Sleep Group Solutions, North Miami Beach, FL, 172 USA). Software was developed to automatically calculate the air/product areas of the oral and 173 pharyngeal cavities for each individual (Doyennette et al., 2011). The tidal volume of each 174 individual was measured with a spirometer (Pulmo System II, MSR, Rungis, France) (Repoux 175 et al., 2012a).

176 Non-stimulated saliva was collected by asking volunteers to swallow the saliva in their mouth

177 before starting and to then spit each $30 \mathrm{~s}$ for $5 \mathrm{~min}$ into ice-chilled vessels. The final saliva 178 weight was measured and the flow rate was calculated as $\mathrm{g} / \mathrm{min}$. Whole saliva samples were 179 centrifuged at $13400 \times \mathrm{g}$ for $5 \mathrm{~min}$ at $4^{\circ} \mathrm{C}$ to remove cellular debris (Eppendorf, model $5415 \mathrm{R}$, 180 Germany). The supernatants were frozen and stored at $-80^{\circ} \mathrm{C}$ before analysis. Protein 181 concentration (expressed in $\mathrm{mg} / \mathrm{mL}$ ) was obtained by standard Bradford protein assay Quick 182 Start (Bio-Rad, France) using bovine serum albumin (Sigma-Aldrich, France) as the standard 183 calibration. The lipolytic (lipolysis), proteolytic (proteolysis), lysozymal (lysozyme) and 184 amylolytic (amylase) activities of individual salivas (expressed in U/mL) were determined as 185 previously described (Neyraud et al., 2012). 
Three replicates per physiological parameter and per panellist were performed. The minimal, median and maximal values of physiological characteristics and associated quartiles are summarized in Table 2.

2.4. Determination of aroma in vivo release kinetics using PTR-MS measurements

190 Release kinetics were obtained using the reference protocol previously defined (referred to as

191 the Nose, Mouth, Swallowing protocol, or N.M.S.) (Déléris et al., 2015): sample inhalation

192 was performed through the panellist's mouth in one short breath and the measurement of 193 aroma release was made within the panellist's nasal cavity.

194 During a session, subjects started with the analysis of a blank sample to get used to the 195 protocol and then tested five samples. The measurement procedure was similar to the one 196 previously described (Déléris et al., 2015): room and breath analyses for $10 \mathrm{~s}$ and $30 \mathrm{~s}$, 197 respectively, followed by sample inhalation and release measurement. During the assay, 198 panellists were allowed to swallow. Between each sample, panellists cleaned their mouth with 199 mineral water (Evian, Danone) and their breath was retested before each new measurement.

200 Some differences with the previous study should be mentioned. First, swallowing events were 201 imposed: $20 \mathrm{~s}$ after sample inhalation for the first swallow, and then every $30 \mathrm{~s}$ until the end 202 of measurement. Secondly, the sample volume was standardised, allowing the quantitative 203 comparison between protocols. Three sessions of $45 \mathrm{~min}$ were planned to obtain three 204 replicates of the five samples for each subject. All the measurements were performed within a 205 21-day period.

206 The High-Sensitivity Proton Transfer Reaction-Mass Spectrometer (PTR-MS) (Ionicon 207 Analytik, Innsbruck, Austria) was operated at a drift tube temperature, voltage and pressure of $20860^{\circ} \mathrm{C}, 600.1( \pm 0.4) \mathrm{V}$ and $2.0( \pm 0.01)$ mbar, respectively $(E / N=151.4( \pm 1.4) \mathrm{Td})$. Nose-space 209 was sampled via two inlets of a stainless nosepiece placed in both nostrils of the assessors. 210 The inlet of the PTR-MS instrument was connected to the sampling device via a 1/16" 
211 PEEK $^{\mathrm{TM}}$ tube maintained at $110^{\circ} \mathrm{C}$. Measurements were performed using the Multiple Ion 212 Detection (MID) mode. For a mass/charge ratio $(\mathrm{m} / \mathrm{z})$ of $21\left(\mathrm{H}_{3} \mathrm{O}^{+}\right)$and $37\left(\mathrm{H}_{2} \mathrm{O}-\mathrm{H}_{3} \mathrm{O}^{+}\right)$, the 213 dwell time per mass was fixed to $0.05 \mathrm{~s}$. The mean signal for $\mathrm{H}_{3} \mathrm{O}^{+}$was $7.8 \times 10^{6} \pm 0.8 \times 10^{6}$ 214 counts per second (cps) and its day-to-day variation along the measurement period was $10 \%$. 215 The signal for $\mathrm{H}_{2} \mathrm{O}-\mathrm{H}_{3} \mathrm{O}^{+}$did not exceed $4 \%$ of the one of $\mathrm{m} / \mathrm{z} 21$ (in agreement with 216 equipment specifications).

217 Using the fragmentation patterns of individual compounds (Table 1), the molecules studied 218 were monitored at $\mathrm{m} / \mathrm{z} 83$ ((Z)-3-hexen-1-ol), $\mathrm{m} / \mathrm{z} 75$ and 103 (ethyl propanoate) and $\mathrm{m} / \mathrm{z} 143$ 219 (2-nonanone). For these four specific masses, a dwell time per mass of $0.1 \mathrm{~s}$ was selected as a 220 compromise between sensitivity for aroma compound detection and appropriate sampling 221 frequency with regard to phenomena to be measured. In addition, $\mathrm{m} / \mathrm{z} 59$ and 93 were 222 monitored with a dwell time per mass of $0.05 \mathrm{~s}$ as markers of panellists' breath (Weel et al., 223 2002) and of balloon material, respectively. With these settings, exhaled air was sampled 224 every $0.6 \mathrm{~s}$, which was assumed to be appropriate regarding the mean duration of the 225 breathing cycle (Doyennette et al., 2011; Sherwood, 2006; Tortora and Anagnostakos, 1990). 226 Mean signal-to-noise ratios varied between 2.0 and 38.0 (depending on the ions), meaning 227 that responses during sample analysis sufficiently exceeded the baseline. These measurements 228 led to the determination of molecule release kinetics, i.e., intensity $I_{t}=f($ time $t)$, for each 229 panellist. Since solution composition was precisely known, aroma compounds were 230 unambiguously detected at the stated $\mathrm{m} / \mathrm{z}$ ratio. For this reason and to facilitate text 231 readability, compound names rather than their $\mathrm{m} / \mathrm{z}$ ratio are used hereafter.

232 For data handling, experimental release curves were divided into three main periods: (i) the 233 phase before the product was inhaled (phase 0); (ii) the phase before the first swallow (phase 234 1); and (iii) the phase after the first swallow (phase 2). For each sample, the mean PTR-MS 235 signal measured during phase 0 was subtracted from the PTR-MS signals obtained during 
phases 1 and 2. Some quantitative release parameters were extracted from each individual 237 release curve and for each phase of product consumption: maximal intensities $\left(\mathrm{I}_{\max 1}\right.$ and $238 \mathrm{I}_{\max 2}$ ), which indicate the maximum concentration reached by a compound; and areas under 239 the curve $\left(\mathrm{AUC}_{1}\right.$ and $\left.\mathrm{AUC}_{2}\right)$, which are related to the total amount of molecule that is 240 released). The ratios between areas under the curve before and after swallowing were also 241 calculated $\left(\mathrm{AUC}_{1} / \mathrm{AUC}_{2}\right)$. Some temporal release parameters such as times at which $\mathrm{I}_{\max }$ 242 occurred $\left(t_{\max 1}\right.$ and $\left.t_{\max 2}\right)$ and initial release rates (Rate ${ }_{1}$ and Rate $e_{2}$, calculated by dividing the $243 I_{\max }$ values with the $t_{\max }$ times) were also determined. Peak widths for each phase were 244 obtained as the difference between the two times at which the intensity was $20 \%$ of $I_{\max }$ (after 245 and before release peak $)\left(\Delta \mathrm{t}_{20 \%_{-} 1}\right.$ and $\left.\Delta \mathrm{t}_{20 \%_{-} 2}\right)$. The difference between the time at which the 246 intensity was $50 \%$ of $\mathrm{I}_{\max }$ after the peak and $\mathrm{t}_{\max }\left(\mathrm{t}_{50 \%-} \mathrm{t}_{\max }\right)$ was also extracted. In addition, 247 standardised release kinetics were obtained by dividing each intensity value of the curve by 248 the corresponding $I_{\max }\left(I_{t_{s} \text { stand }}=I_{t} / I_{\max }\right)$. Standardised areas under the curve $\left(\mathrm{AUC}_{\text {stand. }}\right)$, 249 determined from these standardised kinetics, were used as an indication of persistence 250 behaviour. Because the objective was to compare the persistence of aroma release between 251 molecules, the use of arbitrary units for aroma concentration data was sufficient for data 252 analysis. Since the two ions related to ethyl propanoate behaved in the same way, only the 253 result of $m / z 75$ is presented in the text.

254 Non-parametric descriptive analysis was carried out on datasets and comparative analysis was 255 performed using Kruskal-Wallis tests and the Conover-Iman procedure (multiple paired 256 comparisons) to highlight differences in in vivo release kinetics between molecules. The level 257 of significance was set at $\mathrm{p}<0.05$.

258 3. Modelling 
260 The aroma release model presented in this study was developed to describe aroma release 261 after one inhalation of a gaseous sample through the mouth. It is based on equations that 262 describe mass transfers that occur between the different physiological cavities (mouth, nose, 263 pharynx), considered as interconnected reactors that vary in volume and that exchange 264 matter.

265 A schematic representation of the four physiological cavities involved in the model design, as 266 well as their connections and the mechanisms responsible for aroma release, are given in 267 Figure 2. A schematic representation of mass transfer between air, saliva and mucosa within a 268 physiological cavity is presented in Figure 3. All variables and parameters required for the 269 model simulation are specified in these figures and described in Tables 3 and 4, respectively.

270 The model describes the steps of the experimental protocol: sample inhalation through the 271 mouth, exposure period to the sample until the first swallow, and post-swallow release. 272 Except for the first inhalation, breathing occurs through the nose. Each swallowing step is 273 known to be very short (Martin-Harris, 2006) compared to persistence phenomena (Hodgson 274 et al., 2004; Normand et al., 2004). Swallowing events are thus described as quick 275 simultaneous contractions of the oral cavity and of the pharynx, leading to air expulsion, 276 followed by relaxation and filling with fresh air (Doyennette et al., 2014).

277 Two compartments in the mouth and in the pharynx (mucosa and saliva) and one 278 compartment in the nose (mucosa) were included in the model to introduce a reservoir effect 279 (Figure 2). In each cavity, the air phase was assumed to be in contact with mucosa and/or 280 saliva layers. The proportions of these contact areas can be changed in the model to evaluate 281 the respective contributions of saliva and mucosa. The volumes of the layers involved in the 282 interaction with aroma compounds were expressed as products between compartment areas 283 and layer thicknesses (Eq. (A.12) to Eq. (A.16) in the Appendix A). Similarly to Doyennette 284 et al. (2014), transfer resistances on the air side $\left(1 / \mathrm{k}_{\mathrm{Oa}}, 1 / \mathrm{k}_{\mathrm{Fa}}\right.$ and $\left.1 / \mathrm{k}_{\mathrm{Na}}\right)$ were assumed to be 
negligible when compared to the transfer resistance on the wetted mucosa or saliva sides $286\left(1 / \mathrm{k}_{\mathrm{Om}}, 1 / \mathrm{k}_{\mathrm{Fm}}, 1 / \mathrm{k}_{\mathrm{Nm}}\right.$ and $1 / \mathrm{k}_{\mathrm{Os}}, 1 / \mathrm{k}_{\mathrm{Fs}}$, respectively $)$.

287 To improve the readability of the paper, only generic equations describing phenomena are 288 given in the text. They were written specifically for each compartment to obtain the complete 289 description of aroma release. The details of all model equations are given in the Appendix A.

291 By convention, the air flow rates indicated in Figure 2 are positive if they follow the direction of the arrow. With this convention, air flow rates in the different cavities $\mathrm{Q}_{\mathrm{Oa}}, \mathrm{Q}_{\mathrm{OFa}}, \mathrm{Q}_{\mathrm{Na}}$ and

293 Q $\mathrm{NFa}$ are positive (or null, depending on whether breathing occurs through the nose or the 294 mouth) during inhalation, and negative (or null) during exhalation. Conversely, air flow rate 295 from the trachea $\mathrm{Q}_{\mathrm{Ta}}$ is negative during inhalation and positive during exhalation.

296 Air flow rate in the trachea due to breathing was assumed sinusoidal (Eq. (A.33)). According to Figure 2 and to the experimental protocol, the air flow rate in the mouth is given by the breathing flow rate during the first inhalation and is null afterwards (Eq. (A.34)). The opposite was considered for the air flow rate in the nasal cavity (Eq. (A.35)). According to Figure 2, 300 the air balance in the pharynx at any time is given by the equality of inlet and outlet fluxes 301 (Eq. (A.36)).

\subsection{Saliva in oral cavity}

303 The volume of saliva in the oral cavity gradually increases due to the salivary flow rate Q 304 and abruptly decreases after swallowing. A minimal residual volume of saliva $\mathrm{V}_{\text {Osmin }}$ was 305 assumed to remain in the mouth after swallowing (Doyennette et al., 2014). 3.4.1. Air/mucosa and air/saliva interfaces

308 The interfacial aroma compound concentrations at air/mucosa or air/saliva interfaces were 309 obtained from the partition conditions at the interfaces, using the following generic equations: 


$$
C_{a m}^{*}(t)=\frac{C_{a}(t)}{K_{a m}}, \quad C_{a s}^{*}(t)=\frac{C_{a}(t)}{K_{a s}}
$$

311 Recall that transfer resistances on the air side were assumed negligible, hence, in the air,

312 bulk and interfacial concentrations are identical. Specifically, the air/mucosa interfacial aroma 313 compound concentrations are described by Eq. (A.17), Eq. (A.18) and Eq. (A.19) in oral, 314 nasal or pharyngeal cavities, respectively. The air/saliva interfacial aroma compound 315 concentrations are given by Eq. (A.20) and Eq. (A.21) in the oral or pharyngeal cavities, 316 respectively.

317 Volatile mass fluxes $\phi_{a m}$ and $\phi_{a s}$ between the air and the other compartments (mucosa or 318 saliva) are determined by the resistances located on the mucosa and saliva sides, respectively.

319 They are given by the difference between the mucosa $\left(C_{m}\right)$ or saliva $\left(C_{S}\right)$ concentrations and 320 the interfacial concentrations $\left(C_{a m}^{*}\right)$ or $\left(C_{a s}^{*}\right)$ and are calculated using the following generic 321 equations:

$\phi_{a m}=k_{m} \times A_{a m} \times\left(C_{m}(t)-C_{a m}^{*}(t)\right), \phi_{a s}=k_{s} \times A_{a s} \times\left(C_{s}(t)-C_{a s}^{*}(t)\right)$ Eq. 2 Specifically, in the oral cavity these fluxes are given by Eq. (A.26) and Eq. (A.29), in the pharynx by Eq. (A.28) and Eq. (A.30) and in the nose by Eq. (A.27).

\subsubsection{Mucosa/saliva interface}

Since the mucosa was assumed to be partially wetted by the saliva, aroma partition and flux between mucosa and saliva compartments was also considered in the oral and pharyngeal cavities. Transfer resistances were considered in both saliva and mucosa layers since they are expected to be of comparable magnitude. Interfacial aroma compound concentrations at 330 mucosa/saliva interface were obtained from the partition conditions at the interfaces, using the 331 following generic equation (Figure 3):

$$
C_{s m}^{*}(t)=\frac{C_{m s}^{*}(t)}{K_{m s}}
$$

333 The mucosa/saliva interfacial aroma compound concentrations are described by Eq. (A.22) and Eq. (A.24) in oral or pharyngeal cavities, respectively. The partition coefficients between 
mucosa and saliva were calculated based on partition coefficients with the air phase (Eq.

336 (A.23) and Eq. (A.25)):

$$
K_{m s}=\frac{K_{a s}}{K_{a m}}
$$

338 Since the mucosa was assumed to be partially wetted by the saliva, a volatile flux between

339 saliva and mucosa $\phi_{m s}$ was also considered (Eq. (A.31) in the oral cavity and Eq. (A.32) in 340 the pharyngeal cavity):

$$
\phi_{m s}(t)=k_{e q} \times A_{m s} \times\left(C_{s}(t)-\frac{C_{m}(t)}{K_{m s}}\right)
$$

with $k_{e q}$ being the equivalent mass transfer coefficients between saliva and wetted mucosa, with saliva taken as reference. It includes resistances in both phases in contact and the 344 partition between them (Marin et al., 1999):

$$
\frac{1}{k_{e q}}=\frac{1}{k_{s}}+\frac{K_{m s}}{k_{m}}
$$

\subsection{Volatile mass balances}

According to Figure 2, in each considered cavity the air may exchange aroma compounds with mucosa, saliva and air of connected cavities, as applicable. The generic volatile mass balance for the air in a cavity has the following form, where the term "source" denotes cavities which supply air to the cavity under consideration:

$$
V_{a} \frac{d C_{a}}{d t}=\phi_{a m}+\phi_{a s}+\sum_{\text {source }} Q_{a \text { source }}\left(C_{\text {a source }}-C_{a}\right)
$$

352 For the first inhalation, the variation of aroma concentration in the air in the oral cavity $C_{O a}$ is 353 due to the volatile flux from the inhaled air sample and also to contact with the mucosa and 354 saliva layers (Eq. (A.37)). For the following breathing cycles (through the nose), the mouth is closed (Eq. (A.38)). The mass balance in the air of the nasal cavity is given by Eq. (A.39), with no saliva layer present and the possible source of volatile compounds being the pharynx,

357 during expiration. The pharynx has both saliva and mucosa layers and can exchange air with 
358 the mouth (first inhalation) nose (subsequent breathing) and trachea, as described by Eq. 359 (A.40).

360 Saliva layers in mouth (Eq. (A.41)) and pharynx (Eq. (A.42)) exchange aroma compounds 361 with air and mucosa, according to the generic mass balance:

$$
V_{s} \frac{d C_{F s}(t)}{d t}=-\phi_{a s}(t)-\phi_{m s}(t)
$$

363

with the saliva in the oral cavity being additionally diluted by the fresh saliva flow rate.

Mucosa layers are in contact with air and saliva (except in the nose) and the mass balance for these layers was written on the basis of Eq. 9 (developed as (Eq. A.43), (Eq. A.44) and (Eq. A.45) in the oral, nasal and pharyngeal cavities, respectively):

$$
V_{m} \frac{d C_{m}(t)}{d t}=\phi_{m s}(t)-\phi_{a m}(t)
$$

\subsection{Reference values of the parameters}

The reference values of parameters used for simulations are given in Table 4. Some were taken from experimental data or from the literature, and were estimated when little information was available. For instance, the contact area between air and mucosa in the nose $A_{\text {Nam }}$ was set to $150 \mathrm{~cm}^{2}$ (Levitzky, 2003). Concerning air/mucosa partition properties, values comprised between $5.6 \times 10^{-5}$ and $4.8 \times 10^{-1}$ were found for the air/mucus partition coefficient of butanol and octanol in bullfrog (Hornung et al., 1987). Thus, a typical reference value of $1 \times 10^{-3}$ was selected in this case. Concerning the mucosa layer thickness, values between 500 and $800 \mu \mathrm{m}$ in the mouth and 100 to $200 \mu \mathrm{m}$ for the gingival mucosa were reported (Patel et al., 2012; Shojaei, 1998). It is expected, however, that aroma compounds will not necessarily have time to diffuse in the whole epithelium thickness, so these values were considered as upper limits for the mucosa layer thickness involved in aroma retention. That is why the reference values for mucosa layer thicknesses in the present case in the different compartments were fixed at $50 \mu \mathrm{m}$. On the basis of previous studies (Doyennette et al., 2014), the respiratory frequency $F_{R}$ was set to 0.24 cycles per second. An analysis of model 

kinetics.

\subsection{Numerical methods}

\subsubsection{Solution of model equations}

The dynamic model developed in this study consisted in nine coupled nonlinear differential equations: eight for aroma compound concentrations in air, mucosa (oral, pharynx and nasal cavities) and saliva (oral cavity and pharynx) plus one differential equation for saliva accumulation in the oral cavity between swallowing events. Numeric calculations were performed with Matlab® 8 software (The MathWorks Inc., Natick, MA). The variable step, stiff ODE solver "ode15s" in the Matlab ODE suite (Shampine and Reichelt, 1997) was used with both absolute and relative tolerances for all equations set to $10^{-8}$. Integration step was

394 adjusted internally to meet the specified tolerances while results were provided at the required (e.g. measurement) times. Integration was halted and restarted at each swallowing event to allow abrupt changes in state variables, e.g. saliva volume decrease and air mixing in pharynx

397 related to the quick deglutition process (Doyennette et al., 2014).

\section{3.7.2. Sensitivity analysis}

399 The model contains a total of 27 independent parameters (Table 4), i.e. which cannot be 400 calculated based on other ones (such as a volume being the product of an area and a layer 401 thickness). To assess the importance of these parameters for the prediction of the volatile 402 compound concentration in the nasal cavity (model output) a global Monte Carlo sensitivity 403 analysis was performed as follows. The model output was the relative volatile concentration 404 in the nasal cavity $\left(C_{N a}^{r}\right)$, i.e. the predicted concentration $\left(C_{N a}\right)$ of the aroma compound 405 divided by its maximum value. For a given value $p_{j}$ of each parameter $p$, the relative local 406 sensitivity was defined as: 
408 where $C_{N a}^{r}\left(t_{i}, p_{j}\right)$ is the output of the model calculated for time $t_{i} \in[0,110] s$ with the 409 considered parameter value set to $p_{j}$ and $\delta p$ is a perturbation of the parameter, taken as $10 \%$ 410 of its minimum value indicated in Table 4 . Thus $L\left(p_{j}\right)$ represents an approximation of the 411 partial derivative of the nasal concentration with respect to the considered parameter, taken in 412 absolute value and averaged over time. To make sensitivities dimensionless, of order of unity 413 and hence comparable among various parameters, the right-hand side scaling factor was 414 introduced, based on the reference value of the parameter given in Table 4.

415 The global sensitivity of a parameter was calculated as an average of local sensitivities across 416 a large number of samples taken in the parametric space:

$$
G(p)=\frac{1}{1000} \sum_{j=1}^{1000} L\left(p_{j}\right) \text { Eq. (11) }
$$

418 The parametric space was defined by the range of variation of each parameter indicated in 419 Table 4 and sampled according to a multidimensional "Latin hypercube" method to ensure a 420 uniform representation of all parameter values. Parameters whose range of variation spanned 421 more than one order of magnitude were evenly sampled on a logarithmic rather than linear 422 scale.

423 Automatic sensitivity analysis gives global information on the relative importance of various 424 parameters for the nasal concentration prediction, but provides little insight in the involved 425 phenomena. A manual sensitivity analysis was also performed by varying some of the 426 parameters (specified in the results section) one by one while keeping the others at their 427 reference values. Parameters whose possible variation range was large (sometimes several 428 orders of magnitude) were included in the manual sensitivity analysis, while those relatively 429 well known from the experimental protocol and physiological measurements were kept 430 constant.

$431 \quad$ 3.7.3. Model fitting 
432 To test the ability of the model to reproduce release curves observed for different molecules, 433 some of the least well known parameters were estimated based on release data. The number of 434 estimated parameters was kept at a minimum, however. Volumes, contact areas, respiratory 435 frequency and deglutition times were either known from physiological measurements or 436 imposed by the experimental protocol; these parameters were kept fixed to their reference 437 values indicated in Table 4 . Partition coefficients between air and saliva $\left(K_{\text {Oas }}=K_{\text {Fas }}\right)$ were 438 experimentally determined for the three aroma compounds; these values were used without 439 change. The estimated parameters, assumed to be the same in all cavities, were the transfer 440 coefficient in the saliva ( $k_{O S}=k_{F S}$, the same for all molecules) because in vivo hydrodynamic 441 conditions are poorly known, and parameters related to the mucosa layer: thickness $\left(e_{O m}=\right.$ $442 e_{F m}=e_{N m}$, common to all molecules), transfer coefficient $\left(k_{O m}=k_{F m}=k_{N m}\right.$, also 443 common to all molecules) and air/mucosa partition coefficients $\left(K_{\text {Oam }}=K_{\text {Fam }}=K_{\text {Nam }}\right)$, 444 expected to vary strongly with the physico-chemical properties of the studied compounds and 445 hence specific to each molecule.

446 Model fitting was thus performed simultaneously using data from release experiments with 447 the three molecules, the partition coefficients being specific to each molecule but common to 448 all cavities and the other abovementioned parameters common to all molecules and all 449 cavities. The fitting criterion was the sum of the absolute values of the errors between model 450 predictions and experimental measurements of the compound concentration in the nasal 451 cavity, both normalised by their respective maximum values $\left(C_{N a}^{r}\right)$, because measured data 452 was only available in arbitrary units. Since possible ranges of some of the parameters span up 453 to 4 orders of magnitude (Table 4) a "global" optimisation procedure based on genetic 454 programming was used, namely the "ga" implementation in the Matlab® Global Optimization 455 Toolbox, with default settings (e.g. population of 40 individuals, convergence tolerance $10^{-6}$ ) 456 and the maximum number of generations increased to 200. Parameters whose search range 
(Table 4) spanned more than one order of magnitude were sampled on a logarithmic scale, i.e.

458 the logarithm of the parameter was actually searched for by the optimisation algorithm. Since

459 the considered optimisation algorithm is stochastic, several ( 10) optimisation runs were 460 performed and the one with the best fit was selected. Consistent convergence to similar values 461 of the parameters (usually within $\pm 15 \%$ ) was observed in most runs.

\section{Results and discussion}

\subsection{Molecule specific effects on aroma release kinetics}

As previously highlighted (Déléris et al., 2015), significant differences between aroma compounds in terms of release descriptors were observed (Figure 4).

Differences in $I_{\max 1}$ and $I_{\max 2}$ and in $\mathrm{AUC}_{1}$ and $\mathrm{AUC}_{2}$ were explained by differences in inhaled gaseous concentrations of molecules due to different aqueous concentrations and

468 air/water partition properties. They were thus not shown nor discussed here.

469 Before swallowing (Figure 4-a), no difference between molecules was observed concerning $470 \mathrm{t}_{\max }$. Yet, the peak width $\Delta \mathrm{t}_{20 \%_{1} 1}$ of 2-nonanone was the largest and those of ethyl propanoate 471 the narrowest. After swallowing, differences in release behaviours were more pronounced 472 since some temporal parameters were significantly different between molecules: ethyl 473 propanoate was released the most rapidly and with a quite narrow peak, whereas (Z)-3-hexen474 1-ol had the most delayed release, with the largest peak at $50 \%$ of $\mathrm{I}_{\max }\left(\mathrm{t}_{50 \%-} \mathrm{t}_{\max }\right)$, and 475 2-nonanone had the largest peak at $20 \%$ of $\mathrm{I}_{\max }\left(\Delta \mathrm{t}_{20 \% \_2}\right)$ (Figure 4-b). Initial release rates were 476 molecule-dependent both before and after swallowing (Figure 4-c). Ethyl propanoate was 477 released faster than (Z)-3-hexen-1-ol (before and after swallowing) and 2-nonanone (only 478 before swallowing).

$479 \mathrm{AUC}_{\text {stand, }}$, which can be associated with molecule persistence, also reflected differences in 480 release behaviour: the highest value was obtained for 2-nonanone, highlighting quite 481 persistent release behaviour for this molecule (Figure 4-d). In contrast, ethyl propanoate 
presented the lowest values of $\mathrm{AUC}_{\text {stand. }}$ The $\mathrm{AUC}_{1} / \mathrm{AUC}_{2}$ ratios were higher than 1 for all

483 molecules, meaning that a greater amount was released before swallowing than after.

484 However, a 30-fold increase in $\mathrm{AUC}_{1} / \mathrm{AUC}_{2}$ ratio was observed between 2-nonanone and

485 ethyl propanoate, meaning that the latter was mainly released before swallowing, whereas

486 2-nonanone was released during both phases.

487 All these results were in agreement with previous observations and confirmed the probable 488 existence of retention phenomena for some aroma compounds. To get insight in the exact 489 nature of these interactions, notably in the respective roles of the physicochemical properties 490 of the molecules, of saliva and/or of mucosa characteristics, model simulations and sensitivity 491 analysis were used.

492 We could also mention that from these results, no clear relationship between aroma release 493 and anatomical or physiological parameters was observed

494 4.2. Simulations of aroma compound release kinetics

495 One of the advantages of using a modelling approach is the possible determination of the time 496 variation of variables that could not be experimentally determined, providing insight in the 497 involved mechanisms. Examples of simulated release kinetics obtained with the model in the 498 different compartments of the naso-oro-pharyngeal cavities are presented in Figure 5.

499 As a starting point, model parameters were fixed to their reference values, determined either 500 from data in the literature or experimentally (Table 4). Air/mucosa contact areas in the mouth $501 \mathrm{~A}_{\mathrm{Oam}}$ and in the pharynx $\mathrm{A}_{\text {Fam }}$ were fixed at $10 \%$ of the total area of the mouth $\mathrm{A}_{\mathrm{O}}$ and the 502 pharynx $A_{F}$, respectively, meaning that $90 \%$ of the mouth and pharynx surfaces were wetted 503 by saliva. The resulting kinetics were considered as a reference. The inset on each figure 504 illustrates the first 3 seconds of the release to better understand initial phenomena. Just after 505 sample inhalation through the mouth, the gaseous concentrations of aroma compounds in the 506 pharynx $\mathrm{C}_{\mathrm{Fa}}$ and in the mouth $\mathrm{C}_{\mathrm{Oa}}$ increased (Figures 5-a and 5-d, respectively). In parallel, 
molecules accumulated within mucosa and saliva layers both in the mouth (Figures 5-e and 5-

508 f, respectively) and in the pharynx (Figures 5-b and 5-c, respectively). When the mouth was

509 closed (at $2 \mathrm{~s}$ ), aroma compound gaseous concentration in the air in the mouth started to

510 decrease, as well as in the pharynx. In the mouth, the slow decrease in the gaseous

511 concentration of aroma compounds after $2 \mathrm{~s}$ was due to adsorption on mucosa and saliva

512 layers. In the pharynx, the expiration flow rate accounts for the much faster decrease since it

513 was responsible for the transport of aroma compounds from the pharynx to the nose (increase

514 in aroma compound concentration in the nose $\mathrm{C}_{\mathrm{Na}}$ (Figure 5-g) and, therefore, a decrease in

515 aroma compound concentration in the pharynx $\mathrm{C}_{\mathrm{Fa}}$ (Figure 5-a). The adsorption of aroma

516 compounds on mucosa is also probably involved in this decrease. The pulse in aroma

517 concentration in the nasal cavity led to an increase in aroma concentration within the nasal

518 mucosa layer $\mathrm{C}_{\mathrm{Nm}}$ (Figure 5-h). Yet, aroma compound concentration in the nose air rapidly

519 decreased to zero since air from the lungs was aroma-free and the aroma transfer from the

520 nasal mucosa to the air in the nose (which occurred as aroma concentration in the nasal

521 mucosa progressively decreased; Figure 5-h) was not rapid enough to compensate for the

522 dilution by the breath flow rate. Similar conclusions can be drawn concerning the variation of

523 concentrations in pharynx compartments.

524 The first swallow occurred at $20 \mathrm{~s}$. It led to a sudden decrease in saliva volume in the mouth

$525 \mathrm{~V}_{\mathrm{Os}}$ (Figure 5-i), as well as decreases in aroma compound concentrations in the air within the

526 mouth $\left(\mathrm{C}_{\mathrm{Oa}}\right.$, Figure 5-d) and in saliva in the mouth $\mathrm{C}_{\mathrm{Os}}$ (Figure 5-f) and in the pharynx $\mathrm{C}_{\mathrm{Fs}}$

527 (Figure 5-c). In all mucosa compartments, concentrations $\mathrm{C}_{\mathrm{Fm}}, \mathrm{C}_{\mathrm{Om}}$ and $\mathrm{C}_{\mathrm{Nm}}$ progressively

528 decreased, highlighting the unloading of these compartments (Figures 5-b, 5-e and 5-h, 529 respectively). These mass transfers were probably the limiting steps since aroma

530 concentrations in the different air phases $\mathrm{C}_{\mathrm{Fa}}, \mathrm{C}_{\mathrm{Oa}}$ and $\mathrm{C}_{\mathrm{Na}}$ did not increase (Figures 5-a, 5-d

531 and 5-g, respectively). The saliva volume in the mouth followed a cyclic variation, with a 
532 linear increase due to the saliva flow rate between each swallowing event and a sudden 533 decrease when swallowing occurred.

534 4.3. Sensitivity analysis of the model to physicochemical and physiological parameters

535 Modelling makes it possible to easily test the effect of parameters that govern mass transfers, 536 notably those that cannot be modified when performing in vivo studies. Such a sensitivity 537 analysis can contribute to the determination of the nature of the key factors underlying aroma 538 release and persistence.

$539 \quad$ 4.3.1. Global sensitivity analysis

540 Based on the results of the global sensitivity analysis performed as described in section

541 3.7.2, model parameters were arbitrarily divided in three groups, according to their influence 542 on the shape of the nasal concentration release curve (recall that nasal concentration was 543 always normalized by its maximum value). The first group included 3 most influential 544 parameters, with global relative sensitivities comprised between 0.4 and 0.2 : the air/mucosa 545 partition coefficients in the nose $\left(\mathrm{K}_{\mathrm{Nam}}\right)$ and in the pharynx $\left(\mathrm{K}_{\mathrm{Fam}}\right)$ and the respiratory 546 frequency $\left(\mathrm{F}_{\mathrm{R}}\right)$. The second group included 5 moderately influential parameters, with 547 sensitivities between 0.1 and 0.025 : air/mucosa partition coefficient in the mouth $\left(\mathrm{K}_{\text {Oam }}\right)$, 548 air/saliva partition coefficient in the mouth $\left(\mathrm{K}_{\text {Oas }}\right)$ and pharynx $\left(\mathrm{K}_{\mathrm{Fas}}\right)$, mass transfer 549 coefficient in the mouth $\left(\mathrm{k}_{\mathrm{Os}}\right)$ and the tidal volume $\left(\mathrm{V}_{\mathrm{C}}\right)$. The other parameters listed in Table $550 \quad 4$ had sensitivities less than 0.025 .

551 Overall, these results support the central assumption underlying this work, namely that in 552 absence of any food product, volatile persistence in consumer's exhaled air is mainly related 553 to the interaction between the aroma compound and subject's mucosa, quantified in the model 554 via the air/mucosa partition coefficients. A second important factor, already pointed out in 555 presence of non masticated (Tréléa et al., 2008) and masticated (Doyennette et al., 2014) food 556 products, is the consumer's breath via the respiratory frequency and current breath volume. 
Mass transfer and geometry (volumes, contact areas) appear to play a smaller role in volatile persistence than in release from food products.

\subsubsection{Manual sensitivity analysis}

560 When dealing with mass transfer, the main factors governing molecule transports are the 561 contact area, the driving force (dependent, in particular, on the partition properties of the 562 molecules) and the mass transfer coefficient of the molecules. Simulations were thus 563 performed to evaluate their influence on release kinetics. The ranges of variation of model 564 parameter values were chosen to be in agreement with physicochemical or physiological values (Table 4). Only the effects of these modifications on the simulated release kinetics in

566 the nasal cavity are explained since they correspond to what can be experimentally

567 determined. The variation of aroma concentrations in other compartments were simulated but 568 are not discussed here.

569 First, to better understand the respective roles of the saliva and mucosa compartments, some

570 simulations were performed without any saliva compartment (air/mucosa contact areas in the 571 mouth and in the pharynx were equal to the total surfaces of the mouth and the pharynx, 572 respectively, so contact areas with saliva were equal to zero, Table 4).

573 The absence of saliva as well as the modification of mucosa thickness (10-fold variation 574 factor) did not have an impact on the shape of release kinetics of aroma compounds within the 575 nasal cavity. Differences were mainly observed on mucosa concentration and unloading rates 576 (not shown). For example, mucosa concentrations in the mouth and in the pharynx were 5 to 577 9-fold higher, respectively, without saliva than with saliva, and 10-fold higher or lower when 578 the thickness decreased or increased, respectively. Mucosa compartments also unloaded more rapidly when saliva was not considered or when mucosa thicknesses were lower.

580 The mass transfer coefficient of aroma compounds in mucosa had a greater impact on the 581 release kinetics in the nasal cavity when it increased than when it decreased (not shown). 
With an increased mass transfer coefficient in mucosa, mucosa loading and unloading rates

583 were higher. Since air flow rate remained constant between simulations, mucosa compartments were more rapidly unloaded and the gaseous concentration in the nose was thus lower and decreased more rapidly. The effects with decreased values of mass transfer coefficients were less obvious: below a value of $10^{-6} \mathrm{~m} / \mathrm{s}$, very slow aroma transport prevents any significant amount of aroma compound to be loaded into the mucosa, so there is almost 588 no impact on aroma concentration in the nose.

589 Decreasing the air/mucosa partition properties had a big impact on the nasal concentration of 590 aroma compounds and the shape of release kinetics. A low air/mucosa partition means high 591 affinity of the aroma compound for the mucosa compartment. Most of the aroma compound 592 was thus retained within the mucosa and released very slowly in tiny amounts according to 593 breathing cycles. Persistence was thus long but the actual concentration in the nasal cavity 594 was low. A 100 -fold increase in the air/mucosa partition from $10^{-3}$ had less effect on the 595 aroma concentration in the nose than a 100-fold decrease, due to the fact that the amounts of 596 aroma compound loaded into the mucosa became negligible.

597 These results revealed which parameters related to mucosa had an impact on release kinetics. 598 However, except in the nasal cavity, mucosa is always wetted by a saliva film. Mucosa 599 parameters were thus fixed to their reference values and saliva parameters were modified to 600 evaluate their influence on aroma release kinetics. As a reference, it was assumed that saliva 601 covered $90 \%$ of the mouth and pharynx surfaces.

602 Simulations were performed by increasing this percentage up to $100 \%$ without any significant 603 effect (not shown). When saliva is considered, mucosa concentrations are lower due to: (i) the 604 reduced contact area between air and mucosa and, consequently, lower loading rates of 605 mucosa compartments in the mouth and in the pharynx; and (ii) the fact that part of the aroma 
compound was captured by saliva instead of mucosa. Nevertheless, there was no impact on

607 nasal concentration and release kinetics.

608 100-fold variations in the mass transfer coefficients of molecules in saliva did not affect

609 release kinetics in the nasal cavity (not shown). The only consequences were modifications of

610 aroma concentrations in saliva.

611 Concerning the modifications of air/saliva partition properties, only a 100 -fold decrease

612 significantly modified release kinetics as a consequence of a higher affinity of aroma 613 compounds for saliva. Saliva becomes the main aroma reservoir, supplying aroma compounds

614 to the air in the nasal cavity until the first swallow at $20 \mathrm{~s}$. Aroma concentrations increased in 615 saliva (50-fold and 60-fold factors in the pharynx and the mouth, respectively) and decreased 616 in mucosa (6-fold and 3-fold factors in the pharynx and the mouth, respectively) (not shown).

617 Simulations were also performed by varying mouth and pharynx volumes and the salivary 618 flow rate (in the range of experimental values, determined on panellists), but no significant 619 difference was obtained between simulations (not shown), confirming the absence of effect of 620 these parameters in the range of variation that was tested.

621 On the basis of these results, it can be concluded that both saliva and mucosa had an impact 622 on aroma release when the affinity of aroma compounds for these compartments was 623 sufficiently high. Mechanistic modelling provided insight into the relative time distributions 624 of the aroma compound among these compartments.

625 4.4. Adjustment of simulated release kinetics to experimental data

626 To validate model assumptions, model simulations were fitted to experimental data. Three 627 experimental kinetics were used, each one representing specific release behaviour (related to 628 specific aroma compounds). Several parameters were used as degrees of freedom: the 629 effective mucosa thickness participating to aroma retention, the mass transfer coefficients of 630 aroma compounds in saliva and in mucosa and the air/mucosa partition coefficients of aroma 
compounds. For these parameters, values were assumed to be the same in all physiological cavities (mouth, pharynx and nose).

633 Figures 6-a, 6-b and 6-c indicate the good fit that was obtained between experimental

634 (1 panellist, 1 replicate) and simulated release kinetics of ethyl propanoate, (Z)-3-hexen-1-ol 635 and 2-nonanone, respectively.

636 Concerning fitted parameters, the final value of mucosa thickness was modified (26 $\mu \mathrm{m})$ but 637 remained in a realistic order of magnitude. In a first approach, it was set at a similar value for 638 all physiological cavities (nose, pharynx and mouth) since sensitivity analysis did not show a 639 significant influence of this parameter on release kinetic shape. For further studies, it could 640 perhaps be interesting to more accurately study the impact of this parameter since the nose, 641 mouth and pharynx mucosa are clearly physiologically different.

642 The values of the mass transfer coefficients of aroma compounds reached $6.0 \times 10^{-5} \mathrm{~m} / \mathrm{s}$ in 643 saliva and $4.9 \times 10^{-5} \mathrm{~m} / \mathrm{s}$ in mucosa. They were on the order of magnitude of the one used as a 644 reference for simulations and were the same for the three molecules. This result is in 645 agreement with the fact that these coefficients mainly depend on the hydrodynamics in the 646 system and little on molecule properties (Marin et al., 1999). The fact that the mass transfer 647 coefficient in saliva was higher than the one in mucosa was quite expected and can be 648 explained by the difference in viscosity between saliva and mucus. Yet, the absolute values of 649 these mass transfer coefficients in mucosa and saliva were quite high in comparison with the 650 data in the literature $\left(3 \times 10^{-6} \mathrm{~m} / \mathrm{s}\right)$ (Marin et al., 1999). The high degree of mixing that 651 probably exists in the naso-oro-pharyngeal cavities can account for this discrepancy (the data 652 in the literature were related to in vitro studies).

653 The air/mucosa partition properties of aroma compounds ranged between $4.7 \times 10^{-4}(2$ 654 nonanone) and $6.9 \times 10^{-3}$ (ethyl propanoate), the one of (Z)-3-hexen-1-ol being intermediate. In 655 the case of ethyl propanoate, the air/mucosa partition coefficient increased by a factor of 7 
656 compared to reference values, so that the model correctly predicted the experimental release

657 kinetics. It thus appeared that this molecule has limited interaction with saliva and mucosa.

658 The shape of release kinetics in this case is therefore mainly explained by the pulse of the 659 aroma compound due to sample inhalation and air renewal in the mouth at swallowing (Figure 660 6-a). Concerning 2-nonanone, the 2-fold decrease in the air/mucosa partition value suggests 661 that 2-nonanone interacts more with mucosa than the other two compounds. For (Z)-3-hexen662 1-ol, the value of air/mucosa partition properties after model fitting was only slightly 663 modified in comparison to the reference values and remained thus in the same order of 664 magnitude than the air/saliva partition coefficient.

665 On the basis of these results, we could argue that both air/mucosa and air/saliva partition 666 properties are, at least partly, at the origin of the release behaviours that were observed for the 667 molecules: the ones with the lower affinity for saliva and/or mucosa (highest partition 668 coefficients) had the least persistent behaviour.

669 All these results confirmed that in vivo release behaviours were strongly molecule-dependent 670 and highlighted the fact that different types of interactions with mucosa and/or saliva were 671 involved, depending on the molecule's properties. These simulations were in agreement with 672 previous experimental data, which notably showed the limited retention of ethyl propanoate 673 and the specific retention of 2-nonanone in the oral and pharyngeal cavities (Déléris et al., 674 2015). To improve simulations, further development of the model could be foreseen, notably 675 concerning assumptions on mucosa. This will require experimental determination of mucosa 676 properties.

\section{5. Conclusions}

678 In conclusion, it appears that the proposed model adequately simulated aroma release and 679 retention after the inhalation of a gaseous flavoured sample by panellists. The simulation of 680 the time variation of concentrations that cannot be determined experimentally helped to better 
681 understand the involved phenomena. The sensitivity analysis contributed to distinguish the

682 respective roles of saliva and mucosa on aroma retention phenomena. No clear effect of cavity

683 volumes or saliva flow rate on aroma release kinetics was highlighted in the range of variation

684 of parameters that was tested. But results confirmed the particular role of wetted mucosa can

685 play, depending on aroma compound properties. This study constitutes a first step in

686 understanding aroma persistence and further work is needed to clarify the relationships

687 between the properties of molecules and the type of interactions that are involved. 


\section{Appendix A: model equations}

\begin{tabular}{|c|c|c|c|}
\hline & Oral cavity & Nasal cavity & Pharynx \\
\hline \multicolumn{4}{|l|}{ Volumes } \\
\hline $\begin{array}{l}\text { wetted } \\
\text { mucosa }\end{array}$ & Eq. (A.12) $V_{O m}=e_{O m} \times A_{\text {Oam }}$ & Eq. (A.13) $V_{N m}=e_{N m} \times A_{N a m}$ & Eq. (A.14) $V_{F m}=e_{F m} \times A_{F a m}$ \\
\hline saliva & Eq. (A.15) $V_{O S}=e_{O S} \times A_{\text {Oas }}$ & n. a. & Eq. (A.16) $V_{F S}=e_{F S} \times A_{F a s}$ \\
\hline \multicolumn{4}{|c|}{ Interfacial concentrations } \\
\hline air/mucosa & Eq. (A.17) $C_{\text {Oam }}^{*}(t)=\frac{C_{\text {Oa }}(t)}{K_{\text {Oam }}}$ & Eq. (A.18) $C_{N a m}^{*}(t)=\frac{C_{N a}(t)}{K_{N a m}}$ & Eq. (A.19) $C_{F a m}^{*}(t)=\frac{C_{F a}(t)}{K_{F a m}}$ \\
\hline air/saliva & Eq. (A.20) $C_{\text {Oas }}^{*}(t)=\frac{C_{O a}(t)}{K_{\text {Oas }}}$ & n. a. & Eq. (A.21) $\quad C_{F a s}^{*}(t)=\frac{C_{F a}(t)}{K_{F a s}}$ \\
\hline $\begin{array}{l}\text { mucosa/sal } \\
\text { iva }\end{array}$ & $\begin{array}{ll}\text { Eq. (A.22) } & C_{\text {Osm }}^{*}(t)=\frac{C_{\text {Oms }}^{*}(t)}{K_{\text {Oms }}^{*}} \\
\text { Eq. (A.23) } & K_{\text {Oms }}=\frac{K_{\text {Oas }}}{K_{\text {Oam }}}\end{array}$ & n. a. & $\begin{array}{ll}\text { Eq. (A.24) } & C_{F S m}^{*}(t)=\frac{C_{F m s}^{*}(t)}{K_{F m s}} \\
\text { Eq. (A.25) } & K_{F m s}=\frac{K_{F a s}}{K_{F a m}}\end{array}$ \\
\hline \multicolumn{4}{|c|}{ Volatile mass fluxes } \\
\hline air/mucosa & $\begin{array}{l}\text { Eq. (A.26) } \quad \phi_{\text {oam }}(t)=k_{\text {om }} \times A_{\text {Oam }} \times\left(C_{\text {om }}(t)-\right. \\
\left.C_{\text {Oam }}^{*}(t)\right)\end{array}$ & $\begin{array}{l}\text { Eq. (A.27) } \phi_{N a m}(t)=k_{N m} \times A_{N a m} \times\left(C_{N m}(t)-\right. \\
\left.C_{N a m}^{*}(t)\right)\end{array}$ & Eq. (A.28) $\phi_{F a m}(t)=k_{F m} \times A_{F a m} \times\left(C_{F m}(t)-C_{F a m}^{*}(t)\right)$ \\
\hline air/saliva & Eq. (A.29) $\phi_{\text {oas }}(t)=k_{\text {OS }} \times A_{\text {Oas }} \times\left(C_{\text {OS }}(t)-C_{\text {Oas }}^{*}(t)\right)$ & & Eq. (A.30) $\phi_{F a s}(t)=k_{F S} \times A_{F a s} \times\left(C_{F S}(t)-C_{F a s}^{*}(t)\right)$ \\
\hline $\begin{array}{l}\text { mucosa/sal } \\
\text { iva }\end{array}$ & Eq. (A.31) $\phi_{\text {Oms }}(t)=k_{\text {Oeq }} \times A_{O m s} \times\left(C_{O S}(t)-\frac{C_{O m}(t)}{K_{O m s}}\right)$ & & Eq. (A.32) $\phi_{F m s}(t)=k_{F e q} \times A_{F m s} \times\left(C_{F s}(t)-\frac{C_{F m}(t)}{K_{F m s}}\right)$ \\
\hline \multicolumn{4}{|l|}{$\begin{array}{l}\text { Air flow } \\
\text { rates }\end{array}$} \\
\hline \multirow[t]{2}{*}{ breathing } & \multicolumn{3}{|c|}{ Eq. (A.33) $Q_{T a}(t)=-\pi \times F_{R} \times V c \times \sin \left(2 \times \pi \times F_{R} \times t\right)$} \\
\hline & $\begin{array}{l}\text { Eq. (A.34) } \\
Q_{O a}(t)=Q_{O F a}(t)= \\
\left\{\begin{array}{l}-Q_{T a}(t) \text { if } t \leq 1 /\left(2 \times F_{R}\right) \quad\left(1^{\text {st }} \text { inhalation }\right) \\
0 \quad \text { if } t>1 /\left(2 \times F_{R}\right)(\text { breathing through the nose })\end{array}\right.\end{array}$ & $\begin{array}{l}\text { Eq. (A.35) } \\
Q_{N a}(t)=Q_{N F a}(t)= \\
\left\{\begin{array}{c}0 \text { if } t \leq 1 /\left(2 \times F_{R}\right) \quad\left(1^{\text {st }} \text { inhalation }\right) \\
-Q_{T a} \text { if } t>1 /\left(2 \times F_{R}\right) \text { (breathing through the nose) }\end{array}\right.\end{array}$ & Eq. (A.36) $Q_{O F a}(t)+Q_{N F a}(t)=-Q_{T a}(t)$ \\
\hline \multicolumn{4}{|c|}{ Volatile mass balances } \\
\hline air & $\begin{array}{l}\text { Eq. (A.37) } V_{O a} \times \frac{d C_{O a}(t)}{d t}=\phi_{\text {Oam }}(t)+\phi_{\text {oas }}(t)+ \\
Q_{O a}(t) \times C_{\text {ext }}(t)-Q_{O F a} \times C_{O a}(t) \text { for } t \leq \\
1 /\left(2 \times F_{R}\right)\left(1^{\text {st }} \text { inhalation }\right) \\
\text { Eq. (A.38) } \\
V_{O a} \times \frac{d C_{O a}(t)}{d t}=\phi_{\text {oam }}(t)+\phi_{\text {Oas }}(t) \text { for } t> \\
1 /\left(2 \times F_{R}\right) \text { (other breathing cycles, through the nose) }\end{array}$ & $\begin{array}{l}\text { Eq. (A.39) } \\
V_{N a} \times \frac{d C_{N a}(t)}{d t}= \\
\phi_{N a m}(t)-\left\{\begin{array}{c}Q_{N F a}(t) \times C_{F a}(t)-Q_{N a}(t) \times C_{N a(t)} \\
\text { if } Q_{T a}(t) \geq 0(\text { expiration }) \\
Q_{N F a}(t) \times C_{N a}(t) \\
\text { if } Q_{T a}(t)<0 \text { (inspiration) }\end{array}\right.\end{array}$ & $\begin{array}{l}\text { Eq. (A.40) } \\
V_{F a} \times \frac{d C_{F a}(t)}{d t} \\
=\phi_{F a m}(t)+\phi_{F a s}(t) \\
+ \begin{cases}Q_{O F a}(t) \times C_{O a}(t)+Q_{T a}(t) \times C_{F a}(t) & \text { if } t \leq 1 /\left(2 \times F_{R}\right)\left(1^{\text {st }} \text { inhalation) }\right. \\
Q_{N F a}(t) \times C_{F a}(t) & \text { if } t>1 /\left(2 \times F_{R}\right) \text { and } Q_{T a}(t) \geq 0 \text { (expiration) } \\
Q_{N F a}(t) \times C_{N a}(t)+Q_{T a}(t) \times C_{F a}(t) & \text { if } t>1 /\left(2 \times F_{R}\right) \text { and } Q_{T a}(t)<0 \text { (inspiration) }\end{cases} \end{array}$ \\
\hline saliva & $\begin{array}{l}\text { Eq. (A.41) } V_{O S} \times \frac{d C_{O S}(t)}{d t}=-\left(\phi_{\text {oas }}(t)+\phi_{\text {oms }}(t)+\right. \\
\left.Q_{O S} \times C_{O S}(t)\right)\end{array}$ & n. a. & Eq. (A.42) $V_{F s} \times \frac{d C_{F s}(t)}{d t}=-\phi_{F a s}(t)-\phi_{F m s}(t)$ \\
\hline mucosa & (Eq. A.43) $V_{O m} \times \frac{d C_{O m}(t)}{d t}=\phi_{O m s}(t)-\phi_{O a m}(t)$ & (Eq. A.44) $V_{N m} \times \frac{d C_{N m}(t)}{d t}=-\phi_{N a m}(t)$ & (Eq. A.45) $V_{F m} \times \frac{d C_{F m}(t)}{d t}=\phi_{F m s}(t)-\phi_{F a m}(t)$ \\
\hline
\end{tabular}


691 We gratefully acknowledge the panellists for their contribution to in vivo and sensory 692 measurements. We also thank Gilles Feron from UMR 1324 INRA/AgroSup 693 Dijon/CNRS/Université de Bourgogne Centre des Sciences du Goût et de l'Alimentation 694 (CSGA) for the characterisation of saliva samples, and Gail Wagman for revising the English 695 version of the manuscript.

696 8. References

697 Anker, L., Jurs, P.C., Edwards, P.A., (1990). Quantitative structure-retention relationship 698 studies of odor-active aliphatic compounds with oxygen-containing functional groups. 699 Analytical Chemistry, 62(24), 2676-2684.

700 Barron, D., Pineau, N., Matthey-Doret, W., Ali, S., Sudre, J., Germain, J.C., Kolodziejczyk, 701 E., Pollien, P., Labbe, D., Jarisch, C., Dugas, V., Hartmann, C., Folmer, B., (2012). Impact of 702 crema on the aroma release and the in-mouth sensory perception of espresso coffee. Food \& 703 Function, 3(9), 923-930.

704 Benjamin, O., Silcock, P., Beauchamp, J., Buettner, A., Everett, D.W., (2012). Tongue 705 Pressure and Oral Conditions Affect Volatile Release from Liquid Systems in a Model 706 Mouth. Journal of Agricultural and Food Chemistry, 60(39), 9918-9927.

707 Biasioli, F., Gasperi, F., Aprea, E., Endrizzi, I., Framondino, V., Marini, F., Mott, D., Mark, 708 T., (2006). Correlation of PTR-MS spectral fingerprints with sensory characterisation of 709 flavour and odour profile of "Trentingrana" cheese. Food Quality and Preference, 17(1-2), $710 \quad 63-75$.

711 Borysik, A.J., Briand, L., Taylor, A.J., Scottt, I.M., (2010). Rapid Odorant Release in 712 Mammalian Odour Binding Proteins Facilitates Their Temporal Coupling to Odorant Signals. 713 Journal of Molecular Biology, 404(3), 372-380. 
714 Buettner, A., Beauchamp, J., (2010). Chemical input - Sensory output: Diverse modes of 715 physiology-flavour interaction. Food Quality and Preferences, 21(8), 915-924.

716 Buettner, A., Mestres, M., (2005). Investigation of the Retronasal Perception of Strawberry 717 Aroma Aftersmell Depending on Matrix Composition. Journal of Agricultural and Food 718 Chemistry, 53(5), 1661-1669.

719 Buffo, R.A., Rapp, J.A., Krick, T., Reineccius, G.A., (2005). Persistence of aroma compounds 720 in human breath after consuming an aqueous model aroma mixture. Food Chemistry, 89(1), $721 \quad 103-108$.

722 Chastrette, M., Rallet, E., (1998). Structure-minty odour relationships: Suggestion of an 723 interaction pattern. Flavour and Fragrance Journal, 13(1), 5-18.

724 Corley, R.A., Kabilan, S., Kuprat, A.P., Carson, J.P., Minard, K.R., Jacob, R.E., Timchalk, 725 C., Glenny, R., Pipavath, S., Cox, T., Wallis, C.D., Larson, R.F., Fanucchi, M.V., 726 Postlethwait, E.M., Einstein, D.R., (2012). Comparative Computational Modeling of Airflows 727 and Vapor Dosimetry in the Respiratory Tracts of Rat, Monkey, and Human. Toxicological 728 Sciences, 128(2), 500-516.

729 Cussler, E.L., (1997). Diffusion. Mass Transfer in Fluid Systems. (2ème édition ed). 730 University Press, Cambridge.

731 Déléris, I., Kauffmann, M., Saint Eve, A., Féron, G., Souchon, I., (2015). Experimental 732 approaches to better understand the retention of aroma compounds in oro-naso-pharyngeal 733 cavities in: Buettner, A., Beauchamp, J., Guthrie, B., Lavine, B.K. (Eds.), The Chemical 734 Sensory Informatics of Food: Measurement, Analysis, Integration, Washington DC.

735 Déléris, I., Saint Eve, A., Dakowski, F., Sémon, E., Le Quéré, J.L., Souchon, I., (2011). The 736 dynamics of aroma release during the consumption of candies with different structures. 737 Relationship with temporal perception. Food Chemistry, 127, 1615-1624. 
738 Doyennette, M., De Loubens, C., Déléris, I., Souchon, I., Tréléa, I.C., (2011). Mechanisms explaining the role of viscosity and post-deglutitive pharyngeal residue on in vivo aroma release: A combined experimental and modeling study Food Chemistry, 128(2), 380-390.

Doyennette, M., Déléris, I., Féron, G., Guichard, E., Souchon, I., Tréléa, I.C., (2014). Main individual and product characteristics influencing in-mouth flavour release during eating masticated food products with different textures: mechanistic modelling and experimental validation. Journal of theoretical biology, 340, 209-221.

Espinosa Diaz, M., (2004). Comparison between orthonasal and retronasal flavour perception at different concentrations. Flavour and Fragrance Journal, 19(6), 499-504.

Féron, G., Ayed, C., Qannari, E.M., Courcoux, P., Labouré, H., Guichard, E., (2014). Understanding Aroma Release from Model Cheeses by a Statistical Multiblock Approach on Oral Processing. Plos One, 9(4), e93113.

Ferreira, V., Petka, J., Cacho, J., (2006). Intensity and persistence profiles of flavor compounds in synthetic solutions. Simple model for explaining the intensity and persistence of their aftersmell. Journal of Agricultural and Food Chemistry, 54(2), 489-496.

Foster, K.D., Grigor, J.M.V., Cheong, J.N., Yoo, M.J.Y., Bronlund, J.E., Morgenstern, M.P., (2011). The Role of Oral Processing in Dynamic Sensory Perception. Journal of Food Science, 76(2), R49-R61.

Frank, D.C., Eyres, G.T., Piyasiri, U., Delahunty, C.M., (2012). Effect of food matrix structure and composition on aroma release during oral processing using in vivo monitoring. Flavour and Fragrance Journal, 27(6), 433-444.

Geerts, T., Heyden, Y.V., (2011). In Silico Predictions of ADME-Tox Properties: Drug Absorption. Combinatorial Chemistry \& High Throughput Screening, 14(5), 339-361. 
761 Gierczynski, I., Guichard, E., Labouré, H., (2011). Aroma perception in dairy products: the 762 roles of texture, aroma release and consumer physiology. A review. Flavour and Fragrance 763 Journal, 26(3), 141-152.

764 Halpern, B.P., (2004). Retronasal and orthonasal smelling. ChemoSens, 6(3), 1-7.

765 Harrison, M., (2000). Mathematical models of release and transport of flavors from foods in 766 the mouth to the olfactory epithelium, in: Roberts, D.D., Taylors, A.J. (Eds.), Flavor Release, 767 Washington, DC, pp. 179-191.

768 Harrison, M., Hills, B.P., (1997). Mathematical model of flavor release from liquids 769 containing aroma-binding macromolecules. Journal of Agricultural and Food Chemistry, 45, $770 \quad 1883-1890$.

771 Heath, M.R., (2002). The oral management of food: the bases of oral success and for 772 understanding the sensations that drive us to eat. Food Quality and Preference, 13(7-8), 453773 461.

774 Heenan, S., Soukoulis, C., Silcock, P., Fabris, A., Apréa, E., Cappellin, L., Gasperi, F., 775 Biasioli, F., (2011). PTR-TOF-MS monitoring of in vitro and in vivo flavour release in cereal 776 bars with varying sugar composition. Food Chemistry, 131(2), 477-484.

777 Heenan, S.P., Dufour, J.P., Hamid, N., Harvey, W., Delahunty, C.M., (2009). 778 Characterization of fresh bread flavour: Relationships between sensory characteristics and 779 volatile composition. Food Chemistry, 116(1), 249-257.

780 Heilman, S., Hummel, T., (2004). A new method for comparing orthonasal and retronasal 781 olfaction. Behavioral Neuroscience, 118, 412-419.

782 Hodgson, M., Parker, A., Linforth, R.S.T., Taylor, A.J., (2004). In vivo studies on the long 783 term persistence of volatiles in the breath. Flavour and Fragrance Journal, 19(6), 470-475. 
784 Hodgson, M.D., Langridge, J.P., Linforth, R.S.T., Taylor, A.J., (2005). Aroma release and 785 delivery following the consumption of beverages. Journal of Agricultural and Food 786 Chemistry, 53(5), 1700-1706.

787 Hornung, D.E., Youngentob, S.L., Mozell, M.M., (1987). Olfactory Mucosa-Air Partitioning 788 of Odorants. Brain Research Bulletin, 413(1), 147-154.

789 Hummel, T., (2008). Retronasal perception of odors. chemistry and biodiversity, 5(6), 853790861.

791 Hummel, T., Heilmann, S., Landis, B.N., Reden, J., Frasnelli, J., Small, D.M., Gerber, J., 792 (2006). Perceptual differences between chemical stimuli presented through the ortho- or 793 retronasal route. Flavour and Fragrance Journal, 21(1), 42-47.

794 Keyhani, K., Scherer, P.W., Mozell, M.M., (1997). A numerical model of nasal odorant 795 transport for the analysis of human olfaction. Journal of theoretical biology, 186(3), 279-301.

796 Kraft, P., Bajgrowicz, J.A., Denis, C., Frater, G., (2000). Odds and trends: Recent 797 developments in the chemistry of odorants,. Angewandte Chemie International Edition, 17, $798 \quad 2981-3010$.

799 Kurtz, D.B., Zhao, K., Hornung, D.E., Scherer, P., (2004). Experimental and numerical 800 determination of odorant solubility in nasal and olfactory mucosa. Chemical Senses, 29(9), $801 \quad 763-773$.

802 Levitzky, M.G., (2003). Pulmonary physiology. McGraw-Hill Companies Inc., USA.

803 Marin, M., Baek, I., Taylor, A.J., (1999). Volatile release from aqueous solutions under 804 dynamic headspace dilution conditions. Journal of Agricultural and Food Chemistry, 47(11), $805 \quad 4750-4755$.

806 Martin-Harris, B., (2006). Coordination of respiration and swallowing, GI Motility online 807 www.nature.com. 
808 Medinsky, M.A., Kimbell, J.S., Morris, J.B., Gerde, P., Overton, J.H., (1993). Advances in 809 biologically based models for respiratory-tract uptake of inhaled volatiles. Fundamental and 810 applied toxicology, 20(3), 265-272.

811 Morris, J.B., (2012). Biologically-based modeling insights in inhaled vapor absorption and

812 dosimetry. Pharmacology \& Therapeutics, 136(3), 401-413.

813 Neyraud, E., Palicki, O., Schwartz, C., Nicklaus, S., Peron, G., (2012). Variability of human 814 saliva composition: Possible relationships with fat perception and liking. Archives of Oral 815 Biology, 57(5), 556-566.

816 Normand, V., Avison, S., Parker, A., (2004). Modeling the Kinetics of Flavour Release during 817 Drinking. Chemical Senses, 29(3), 235-245.

818 Obata, K., Sugano, K., Saitoh, R., Higashida, A., Nabuchi, Y., Machida, M., Aso, Y., (2005).

819 Prediction of oral drug absorption in humans by theoretical passive absorption model. 820 International Journal of Pharmaceutics, 293(1-2), 183-192.

821 Patel, V.F., Liu, F., Brown, M.B., (2012). Modeling the oral cavity: In vitro and in vivo 822 evaluations of buccal drug delivery systems. journal of controlled release, 161(3), 746-756.

823 Repoux, M., Laboure, H., Courcoux, P., Andriot, I., Semon, E., Yven, C., Feron, G., 824 Guichard, E., (2012a). Combined effect of cheese characteristics and food oral processing on 825 in vivo aroma release. Flavour and Fragrance Journal, 27(6), 414-423.

826 Repoux, M., Sémon, E., Féron, G., Guichard, E., Labouré, H., (2012b). Inter-individual 827 variability in aroma release during sweet mint consumption. Flavour and Fragrance Journal, $828 \quad 27,40-46$.

829 Rognon, C., Chastrette, M., (1994). Structure-odor relationships - a highly predictive 830 tridimensional interaction-model for the bell-pepper note. European Journal of medicinal 831 chemistry, 29(7-8), 595-609. 
832 Sanz, G., Thomas-Danguin, T., Hamdani, E.H., Le Poupon, C., Briand, L., Pernollet, J.C., 833 Guichard, E., Tromelin, A., (2008). Relationships between molecular structure and perceived 834 odor quality of ligands for a human olfactory receptor. Chemical Senses, 33(7), 639-653.

835 Shampine, L.F., Reichelt, M.W., (1997). The MATLAB ODE Suite. SIAM Journal on 836 Scientific Computing, 18, 1-22.

837 Sherwood, L., (2006). Fundamentals of physiology: a human perspective. Thomson 838 Brooks/cole, Belmont, USA.

839 Shojaei, A.H., (1998). Buccal mucosa as a route for systemic drug delivery: a review. Journal 840 of Pharmaceutical Sciences, 1(1), 15-30.

841 Sun, B.C., Halpern, B.P., (2005). Identification of air phase retronasal and orthonasal odorant 842 pairs. Chemical Senses, 30(8), 693-706.

843 Takano, R., Sugano, K., Higashida, A., Hayashi, Y., Machida, M., Aso, Y., Yamashita, S., 844 (2006). Oral absorption of poorly water-soluble drugs: Computer simulation of fraction 845 absorbed in humans from a miniscale dissolution test. Pharmaceutical Research, 23(6), 11448461156.

847 Tortora, G.J., Anagnostakos, N.P., (1990). Principles of anatomy and physiology Harper848 Collins, New-York.

849 Tréléa, I.C., Atlan, S., Déléris, I., Saint-Eve, A., Marin, M., Souchon, I., (2008). Mechanistic 850 mathematical model for in vivo aroma release during eating of semi-liquid foods. Chemical $851 \quad$ Senses, 33(2), 181-192.

852 Tromelin, A., Merabtine, Y., Andriot, I., Lubbers, S., Guichard, E., (2010). Retention-release 853 equilibrium of aroma compounds in polysaccharide gels: Study by quantitative structure854 activity/property relationships approach. Flavour and Fragrance Journal, 25(6), 431. 
855 Visschers, R.W., Jacobs, M.A., Frasnelli, J., Hummel, T., Burgering, M., Boelrijk, A.E.M., 856 (2006). Cross-Modality of Texture and Aroma Perception Is Independent of Orthonasal or 857 Retronasal Stimulation. Journal of Agricultural and Food Chemistry, 51(14), 5509-5515.

858 Weel, K.G.C., Boelrijk, A.E.M., Alting, A.C., Van Mil, P.J.J.M., Burrows, H.D., Gruppen, 859 H., Voragen, A.G.J., Smit, G., (2002). Flavor Release and Perception of Flavored Whey 860 Protein Gels: Perception Is Determined by Texture Rather than by Release. Journal of 861 Agricultural and Food Chemistry, 50(18), 5149-5155.

862 Welge-Lüssen, A., Ebnöther, M., Wolfensberger, M., Hummel, T., (2009). Swallowing Is 863 Differentially Influenced by Retronasal Compared with Orthonasal Stimulation in 864 Combination with Gustatory Stimuli. Chemical Senses, 34, 499-502.

865 Wright, K.M., Hills, B.P., (2003). Modelling flavour release from a chewed bolus in the 866 mouth: Part II. The release kinetics. International Journal of Food Science and Technology, $867 \quad 38(3), 361-368$.

868 Yabuki, M., Scott, D.J., Briand, L., Taylor, A.J., (2011). Dynamics of Odorant Binding to 869 Thin Aqueous Films of Rat-OBP3. Chemical Senses, 36(7), 659-671. 
870 Table 1: Physicochemical properties of aroma compounds used in the present study.

\begin{tabular}{|c|c|c|c|c|c|c|c|c|}
\hline $\begin{array}{c}\text { Aroma } \\
\text { compounds }\end{array}$ & $\begin{array}{l}\text { Chemical } \\
\text { formulae }\end{array}$ & $\begin{array}{l}\text { Chemical } \\
\text { structures }\end{array}$ & $\begin{array}{c}\text { Molecular } \\
\text { weights } \\
\text { (g/mol) }\end{array}$ & $\begin{array}{c}\log \\
P^{1}\end{array}$ & $\begin{array}{c}\text { PTR-MS }^{2} \\
\text { fragmentation: } \\
\text { main m/z peaks } \\
\text { (relative } \\
\text { abundance) } \\
\end{array}$ & $\begin{array}{l}\text { Air/water } \\
\text { partition } \\
\text { coefficient } \\
\left(25^{\circ} \mathrm{C}\right)^{1}\end{array}$ & $\begin{array}{c}\text { Experimental } \\
\text { air/water partition } \\
\text { coefficient } K_{a w} \\
\left(\times 10^{-3}\right)\left(37^{\circ} C\right)^{3}\end{array}$ & $\begin{array}{c}\text { Experimental } \\
\text { air/saliva partition } \\
\text { caefficient } K_{a s} \\
\left(\times 10^{-3}\right)\left(37^{\circ} C\right)^{3}\end{array}$ \\
\hline (Z)-3-Hexen-1-ol & $\mathrm{C}_{6} \mathrm{H}_{12} \mathrm{O}$ & & 100.16 & 1.61 & 55 (100); 83 (39) & $0.6310^{-3}$ & $0.78 \pm 0.07$ & $0.76 \pm 0.12$ \\
\hline Ethyl propanoate & $\mathrm{C}_{5} \mathrm{H}_{10} \mathrm{O}_{2}$ & & 102.13 & 1.21 & 75 (100); 103 (20) & $15.910^{-3}$ & $14.9 \pm 1.4$ & $12.9 \pm 5.5$ \\
\hline 2-Nonanone & $\mathrm{C}_{9} \mathrm{H}_{18} \mathrm{O}$ & & 142.24 & 3.14 & $143(100) ; 41(20)$ & $11.110^{-3}$ & $19.6 \pm 8.4$ & $9.7 \pm 1.39$ \\
\hline
\end{tabular}

$871^{1}$ : estimation with EPI Suite ${ }^{\mathrm{TM}}$ programme

872 22: PTR-MS: Proton Transfer Reaction-Mass Spectrometry

873 3: from (Déléris et al., 2015) 
874 Table 2: Minimal, median and maximal values of the physiological characteristics of 875 panellists and associated quartiles.

\begin{tabular}{|c|c|c|c|c|c|c|}
\hline & Physiological parameters & $\min$ & Q1 & median & Q3 & $\max$ \\
\hline & $\mathrm{V}_{\mathrm{C}}(\mathrm{L})$ & 0.49 & 0.54 & 0.80 & 0.86 & 0.93 \\
\hline & $\mathrm{V}_{\text {nose }}\left(\mathrm{cm}^{3}\right)$ & 5.8 & 9.5 & 11.1 & 13.1 & 16.8 \\
\hline & $\mathrm{V}_{\text {mouth }}\left(\mathrm{cm}^{3}\right)$ & 33.1 & 35.5 & 39.3 & 56.7 & 69.8 \\
\hline & $\mathrm{V}_{\text {pharynx }}\left(\mathrm{cm}^{3}\right)$ & 16.8 & 24.3 & 27.4 & 30.2 & 34.8 \\
\hline$\frac{\omega}{2}$ & Salivary flux (g/min) & 0.32 & 0.44 & 0.54 & 0.66 & 0.87 \\
\hline שै & Antioxidant (eq mM Trolox) & 75.4 & 90.7 & 105.7 & 127.5 & 137.3 \\
\hline $\bar{E}$ & Lipolysis $(\mathrm{mU} / \mathrm{mL})$ & 0.04 & 0.08 & 0.15 & 0.19 & 0.27 \\
\hline こี & Amylase (U/mL) & 67.4 & 88.7 & 124.8 & 148.6 & 196.0 \\
\hline$\vec{\approx}$ & Proteolysis $(\mathrm{U} / \mathrm{mL})$ & 1.6 & 1.9 & 4.1 & 4.8 & 11.2 \\
\hline & Lysozyme (U/mL) & 313.2 & 332.2 & 413.9 & 444.1 & 462.1 \\
\hline 5 & Proteins $(\mathrm{mg} / \mathrm{mL})$ & 0.46 & 0.55 & 0.81 & 0.94 & 1.15 \\
\hline
\end{tabular}

876 


\begin{tabular}{|c|c|c|}
\hline Symbol & Unit & Definition \\
\hline $\mathrm{C}_{\mathrm{Fa}}$ & $\mathrm{g} / \mathrm{cm}^{3}$ & Aroma concentration in the air in the pharynx \\
\hline $\mathrm{C}_{\mathrm{Fm}}$ & $\mathrm{g} / \mathrm{cm}^{3}$ & Aroma concentration in the wetted mucosa in the pharynx \\
\hline $\mathrm{C}_{\mathrm{Fs}}$ & $\mathrm{g} / \mathrm{cm}^{3}$ & Aroma concentration in saliva in the pharynx \\
\hline $\mathrm{C}_{\text {Fam }}^{*}$ & $\mathrm{~g} / \mathrm{cm}^{3}$ & Aroma concentration at the air/wetted mucosa interface in the pharynx \\
\hline $\mathrm{C}_{\text {Fas }}^{*}$ & $\mathrm{~g} / \mathrm{cm}^{3}$ & Aroma concentration at the air/saliva interface in the pharynx \\
\hline $\mathrm{C}_{\mathrm{Fms}}^{*}$ & $\mathrm{~g} / \mathrm{cm}^{3}$ & $\begin{array}{l}\text { Aroma concentration at the wetted mucosa/saliva interface in the pharynx, on the } \\
\text { mucosa side }\end{array}$ \\
\hline $\mathrm{C}_{\mathrm{Fsm}}^{*}$ & $\mathrm{~g} / \mathrm{cm}^{3}$ & $\begin{array}{l}\text { Aroma concentration at the wetted mucosa/saliva interface in the pharynx, on the } \\
\text { saliva side }\end{array}$ \\
\hline $\mathrm{C}_{\mathrm{Oa}}$ & $\mathrm{g} / \mathrm{cm}^{3}$ & Aroma concentration in the air in the oral cavity \\
\hline $\mathrm{C}_{\mathrm{Om}}$ & $\mathrm{g} / \mathrm{cm}^{3}$ & Aroma concentration in the wettedd mucosa in the oral cavity \\
\hline $\mathrm{C}_{\mathrm{Os}}$ & $\mathrm{g} / \mathrm{cm}^{3}$ & Aroma concentration in saliva in the oral cavity \\
\hline $\mathrm{C}^{*}$ Oam & $\mathrm{g} / \mathrm{cm}^{3}$ & Aroma concentration at the air/wetted mucosa interface in the oral cavity \\
\hline $\mathrm{C}_{\text {Oas }}^{*}$ & $\mathrm{~g} / \mathrm{cm}^{3}$ & Aroma concentration at the air/saliva interface in the oral cavity \\
\hline $\mathrm{C}_{\text {Oms }}^{*}$ & $\mathrm{~g} / \mathrm{cm}^{3}$ & $\begin{array}{l}\text { Aroma concentration at the wetted mucosa/saliva interface in the oral cavity, on } \\
\text { the mucosa side }\end{array}$ \\
\hline $\mathrm{C}^{*}{ }_{\mathrm{Osm}}$ & $\mathrm{g} / \mathrm{cm}^{3}$ & $\begin{array}{l}\text { Aroma concentration at the wetted mucosa/saliva interface in the oral cavity, on } \\
\text { the saliva side }\end{array}$ \\
\hline $\mathrm{C}_{\mathrm{Na}}$ & $\mathrm{g} / \mathrm{cm}^{3}$ & Aroma concentration in the air in the nose \\
\hline $\mathrm{C}_{\mathrm{Nm}}$ & $\mathrm{g} / \mathrm{cm}^{3}$ & Aroma concentration in the mucosa in the nose \\
\hline $\mathrm{C}_{\mathrm{Nam}}^{*}$ & $\mathrm{~g} / \mathrm{cm}^{3}$ & Aroma concentration at the air/mucosa interface in the nose \\
\hline $\mathrm{C}_{\mathrm{Ta}}$ & $\mathrm{g} / \mathrm{cm}^{3}$ & Aroma concentration in the trachea \\
\hline $\mathrm{Q}_{\mathrm{Na}}$ & $\mathrm{cm}^{3} / \mathrm{s}$ & Air flow rate into the nasal cavity \\
\hline $\mathrm{Q}_{\mathrm{NFa}}$ & $\mathrm{cm}^{3} / \mathrm{s}$ & Air flow rate from the nasal cavity to the pharynx \\
\hline $\mathrm{Q}_{\mathrm{Oa}}$ & $\mathrm{cm}^{3} / \mathrm{s}$ & Air flow rate into the oral cavity ( $1^{\text {st }}$ inhalation) \\
\hline $\mathrm{Q}_{\mathrm{OFa}}$ & $\mathrm{cm}^{3} / \mathrm{s}$ & Air flow rate from the oral cavity to the pharynx \\
\hline $\mathrm{Q}_{\mathrm{Ta}}$ & $\mathrm{cm}^{3} / \mathrm{s}$ & Air flow rate from the trachea \\
\hline $\mathrm{t}$ & $\mathrm{s}$ & Time \\
\hline$t_{\text {deg }}$ & $\mathrm{s}$ & Swallowing moment \\
\hline$\phi_{\text {Fam }}$ & $\mathrm{g} / \mathrm{s}$ & Volatile mass flux between the air and the wetted mucosa in the pharynx \\
\hline$\phi_{\text {Fas }}$ & $\mathrm{g} / \mathrm{s}$ & Volatile mass flux between the air and the saliva in the pharynx \\
\hline$\phi_{\text {Fms }}$ & $\mathrm{g} / \mathrm{s}$ & Volatile mass flux between the wetted mucosa and the saliva in the pharynx \\
\hline$\phi_{\mathrm{Nam}}$ & $\mathrm{g} / \mathrm{s}$ & Volatile mass flux between the air and mucosa in the nasal cavity \\
\hline$\phi_{\text {Oam }}$ & $\mathrm{g} / \mathrm{s}$ & Volatile mass flux between the air and the wetted mucosa in the oral cavity \\
\hline$\phi_{\text {Oas }}$ & $\mathrm{g} / \mathrm{s}$ & Volatile mass flux between the air and the saliva in the oral cavity \\
\hline$\phi_{\text {Oms }}$ & $\mathrm{g} / \mathrm{s}$ & Volatile mass flux between the wetted mucosa and the saliva in the oral cavity \\
\hline
\end{tabular}




\begin{tabular}{|c|c|c|c|c|c|c|}
\hline Symbol & Unit & Definition & $\begin{array}{l}\text { Reference } \\
\text { value }\end{array}$ & Range of variation & $\begin{array}{c}\text { Global sensitivity } \\
\text { index (from } \\
\text { Monte-Carlo } \\
\text { analysis) }^{\mathrm{a}}\end{array}$ & Source \\
\hline $\mathrm{A}_{\mathrm{F}}$ & $\mathrm{cm}^{2}$ & Total area of the pharynx & 65 & $32.5 \ldots 130$ & + & $\begin{array}{c}\text { (Doyennette } \text { et al., } \\
\text { 2014) }\end{array}$ \\
\hline $\mathrm{A}_{\text {Fam }}$ & $\mathrm{cm}^{2}$ & Air/mucosa contact area in pharynx & $=0.1 \times A_{F}$ & $0.1 \times A_{F}-A_{F}$ & + & - \\
\hline $\mathrm{A}_{\mathrm{Fas}}$ & $\mathrm{cm}^{2}$ & Air/saliva contact area in pharynx & $=A_{F}-A_{F a m}$ & l & + & - \\
\hline $\mathrm{A}_{\mathrm{Fms}}$ & $\mathrm{cm}^{2}$ & Mucosa/saliva contact area in pharynx & $=A_{F}-A_{F a m}$ & 1 & + & - \\
\hline $\mathrm{A}_{\mathrm{Nam}}$ & $\mathrm{cm}^{2}$ & Air/mucosa contact area in nose & 150 & $75 \ldots 300$ & + & (Levitzky, 2003) \\
\hline $\mathrm{A}_{\mathrm{O}}$ & $\mathrm{cm}^{2}$ & Total area in oral cavity & 116 & $58 \ldots 232$ & + & $\begin{array}{c}\text { (Doyennette } \text { et al., } \\
\text { 2014) }\end{array}$ \\
\hline $\mathrm{A}_{\text {Oam }}$ & $\mathrm{cm}^{2}$ & Air/mucosa contact area in oral cavity & $=0.1 \times A_{O}$ & $0.1 \times A_{O}-A_{O}$ & + & - \\
\hline $\mathrm{A}_{\mathrm{Oas}}$ & $\mathrm{cm}^{2}$ & Air/saliva contact area in oral cavity & $=A_{O}-A_{O a m}$ & 1 & + & - \\
\hline $\mathrm{A}_{\mathrm{Oms}}$ & $\mathrm{cm}^{2}$ & Mucosa/saliva contact area in oral cavity & $=A_{O}-A_{O a m}$ & 1 & + & - \\
\hline $\mathrm{C}_{\mathrm{ext}}$ & $\mu \mathrm{g} / \mathrm{cm}^{3}$ & Aroma concentration in air & 1 & $0.5 \ldots 2$ & + & Experimental value \\
\hline $\mathrm{e}_{\mathrm{Fm}}$ & $\mathrm{cm}$ & Thickness of wetted mucosa in pharynx & $510^{-3}$ & $510^{-4} \ldots 510^{-2}$ & + & (Shojaei, 1998) \\
\hline $\mathrm{e}_{\mathrm{Fs}}$ & $\mathrm{cm}$ & Thickness of saliva layer in pharynx & $=V_{F s} / A_{F a s}$ & - & 1 & - \\
\hline $\mathrm{e}_{\mathrm{Om}}$ & $\mathrm{cm}$ & Thickness of wetted mucosa in oral cavity & $510^{-3}$ & $510^{-4} \ldots 510^{-2}$ & + & (Shojaei, 1998) \\
\hline $\mathrm{e}_{\mathrm{Os}}$ & $\mathrm{cm}$ & Thickness of saliva layer in oral cavity & $=V_{O S} / A o_{F a s}$ & 1 & 1 & - \\
\hline $\mathrm{e}_{\mathrm{Nm}}$ & $\mathrm{cm}$ & Thickness of mucosa in nasal cavity & $510^{-3}$ & $510^{-4} \ldots 510^{-2}$ & + & (Shojaei, 1998) \\
\hline $\mathrm{F}_{\mathrm{R}}$ & Cycle/s & Respiratory frequency & 0.24 & $0.12 \ldots 0.48$ & +++ & $\begin{array}{c}\text { (Doyennette } \text { et al., } \\
\text { 2014) }\end{array}$ \\
\hline $\mathrm{K}_{\text {Fam }}$ & & Air/wetted mucosa partition coefficient in pharynx & $10^{-3}$ & $10^{-5} \ldots 10^{-1}$ & +++ & (Hornung et al., 1987) \\
\hline $\mathrm{K}_{\mathrm{Fas}}$ & & Air/saliva partition coefficient in pharynx & $510^{-3}$ & $510^{-4} \ldots 510^{-2}$ & ++ & Experimental values \\
\hline $\mathrm{K}_{\mathrm{Fms}}$ & & $\begin{array}{l}\text { Wetted mucosa/saliva partition coefficient in } \\
\text { pharynx }\end{array}$ & $=K_{\text {Fas }} / K_{\text {Fam }}$ & 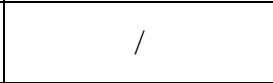 & I & - \\
\hline $\mathrm{K}_{\mathrm{Nam}}$ & & Air/ mucosa partition coefficient in nasal cavity & $10^{-3}$ & $10^{-5} \ldots 10^{-1}$ & +++ & (Hornung et al., 1987) \\
\hline $\mathrm{K}_{\text {Oam }}$ & & $\begin{array}{l}\text { Air/wetted mucosa partition coefficient in oral } \\
\text { cavity }\end{array}$ & $10^{-3}$ & $10^{-5} \ldots 10^{-1}$ & ++ & (Hornung et al., 1987) \\
\hline $\mathrm{K}_{\text {Oas }}$ & & Air/saliva partition coefficient in oral cavity & $510^{-3}$ & $510^{-4} \ldots 510^{-2}$ & ++ & Experimental values \\
\hline $\mathrm{K}_{\mathrm{Oms}}$ & & $\begin{array}{l}\text { Wetted mucosa/saliva partition coefficient in oral } \\
\text { cavity }\end{array}$ & $=K_{\text {Oas }} / K_{\text {Oam }}$ & / & I & - \\
\hline $\mathrm{k}_{\mathrm{Fa}}$ & $\mathrm{m} / \mathrm{s}$ & Mass transfer coefficient in air in pharynx & $10^{-2}$ & I & I & (Cussler, 1997) \\
\hline $\mathrm{k}_{\mathrm{Fm}}$ & $\mathrm{m} / \mathrm{s}$ & $\begin{array}{l}\text { Mass transfer coefficient in wetted mucosa in } \\
\text { pharynx }\end{array}$ & $10^{-6}$ & $10^{-8} \ldots 10^{-4}$ & + & (Cussler, 1997) \\
\hline $\mathrm{k}_{\mathrm{Fs}}$ & $\mathrm{m} / \mathrm{s}$ & Mass transfer coefficient in saliva in pharynx & $10^{-6}$ & $10^{-8} \ldots 10^{-4}$ & + & (Cussler, 1997) \\
\hline $\mathrm{k}_{\mathrm{Feq}}$ & $\mathrm{m} / \mathrm{s}$ & $\begin{array}{l}\text { Equivalent mass transfer coefficient between saliva } \\
\text { and wetted mucosa in pharynx }\end{array}$ & \multicolumn{2}{|c|}{$1 / k_{F e q}=1 / k_{F s}+K_{F m s} / k_{F m}$} & I & (Marin et al., 1999) \\
\hline $\mathrm{k}_{\mathrm{Na}}$ & $\mathrm{m} / \mathrm{s}$ & Mass transfer coefficient in air in nasal cavity & $10^{-2}$ & I & I & (Cussler, 1997) \\
\hline $\mathrm{k}_{\mathrm{Nm}}$ & $\mathrm{m} / \mathrm{s}$ & Mass transfer coefficient in mucosa in nasal cavity & $10^{-6}$ & $10^{-8} \ldots 10^{-4}$ & + & (Cussler, 1997) \\
\hline $\mathrm{k}_{\mathrm{Oa}}$ & $\mathrm{m} / \mathrm{s}$ & Mass transfer coefficient in air in the oral cavity & $10^{-6}$ & 1 & I & (Cussler, 1997) \\
\hline $\mathrm{k}_{\mathrm{Om}}$ & $\mathrm{m} / \mathrm{s}$ & $\begin{array}{l}\text { Mass transfer coefficient in wetted mucosa in the } \\
\text { oral cavity }\end{array}$ & $10^{-6}$ & $10^{-8} \ldots 10^{-4}$ & + & (Cussler, 1997) \\
\hline $\mathrm{k}_{\mathrm{Os}}$ & $\mathrm{m} / \mathrm{s}$ & Mass transfer coefficient in saliva in oral cavity & $10^{-6}$ & $10^{-8} \ldots 10^{-4}$ & ++ & (Cussler, 1997) \\
\hline $\mathrm{k}_{\text {Oeq }}$ & $\mathrm{m} / \mathrm{s}$ & $\begin{array}{l}\text { Equivalent mass transfer coefficient between saliva } \\
\text { and wetted mucosa in oral cavity }\end{array}$ & \multicolumn{2}{|c|}{$1 / k_{O e q}=1 / k_{O s}+K_{O m s} / k_{O m}$} & l & (Marin et al., 1999) \\
\hline $\mathrm{Q}_{\mathrm{Os}}$ & $\mathrm{cm}^{3} / \mathrm{s}$ & Average rate of saliva flow rate & 0.6 & $0.15 \ldots 2.4$ & + & Experimental values \\
\hline $\mathrm{t}_{\mathrm{deg}}$ & $\mathrm{s}$ & Swallowing moment & $20,50,80,110$ & l & I & $\begin{array}{l}\text { Defined by the } \\
\text { experimental protocol }\end{array}$ \\
\hline $\mathrm{V}_{\mathrm{C}}$ & $\mathrm{cm}^{3}$ & Current breath volume & 800 & $400 \ldots 1600$ & ++ & Experimental values \\
\hline $\mathrm{V}_{\mathrm{Fa}}$ & $\mathrm{cm}^{3}$ & Volume of air in the pharynx & 30 & $15 \ldots 60$ & + & Experimental values \\
\hline $\mathrm{V}_{\mathrm{Fm}}$ & $\mathrm{cm}^{3}$ & Volume of wetted mucosa in pharynx & $=e_{F m} \times A_{F a m}$ & I & I & - \\
\hline $\mathrm{V}_{\mathrm{Fs}}$ & $\mathrm{cm}^{3}$ & Volume of saliva in pharynx & 0.2 & $0.1 \ldots 0.4$ & + & - \\
\hline $\mathrm{V}_{\mathrm{Na}}$ & $\mathrm{cm}^{3}$ & Volume of air in nasal cavity & 20 & $10 \ldots 40$ & + & - \\
\hline
\end{tabular}




\begin{tabular}{|c|c|c|c|c|c|c|}
\hline $\mathrm{V}_{\mathrm{Nm}}$ & $\mathrm{cm}^{3}$ & Volume of mucosa in nasal cavity & $=e_{N m} \times A_{N a m}$ & / & I & - \\
\hline $\mathrm{V}_{\mathrm{Oa}}$ & $\mathrm{cm}^{3}$ & Volume of air in oral cavity & 40 & $20 \ldots 80$ & + & Experimental value \\
\hline $\mathrm{V}_{\mathrm{Om}}$ & $\mathrm{cm}^{3}$ & Volume of wetted mucosa in oral cavity & $=e_{O m} \times A_{O a m}$ & 1 & 1 & - \\
\hline $\mathrm{V}_{\mathrm{Os}}$ & $\mathrm{cm}^{3}$ & Volume of saliva in oral cavity & $=e_{O s} \times A_{\text {Oas }}$ & l & I & - \\
\hline $\mathrm{V}_{\text {Osmin }}$ & $\mathrm{cm}^{3}$ & $\begin{array}{l}\text { Minimal volume of saliva in oral cavity after } \\
\text { swallowing }\end{array}$ & 0.2 & $0.1 \ldots 0.4$ & + & $\begin{array}{l}\text { (Doyennette et al., } \\
\text { 2014) }\end{array}$ \\
\hline
\end{tabular}

880

$881{ }^{a}$ Global sensitivity index: +++ means a highly influent parameter (sensitivity index between

8820.4 and 0.2 ); ++ means a moderately influent parameter (sensitivity index between 0.1 and

$8830.025)$; + was used for parameters with sensitivity index below 0.025 . 


\section{Figure captions}

Fig. 1: Schematic representation of the experimental set-up for the preparation of gaseous samples with controlled volume.

Fig. 2: Schematic representation of the interconnected compartments of the naso-oropharyngeal cavities and the mechanisms involved in aroma release during the inhalation of gaseous samples.

Fig. 3: Schematic representation of the balances between the different compartments. Bold red lines represent concentration profiles and horizontal dotted lines represent the limits of boundary layers where mass transfer resistance was considered.

Fig. 4: Comparison of parameters extracted from release kinetics that significantly differ between ions (means and associated standard deviations). (a) $t_{\max 1}$ and $\Delta t_{20 \% \_1}$, before swallowing; (b) $t_{\max 2}, \Delta t_{20 \% \_2}$ and $t_{50 \%}-t_{\max 2}$, after swallowing; (c) initial release rates Rate 1 and $\mathrm{Rate}_{2}$; (d) $\mathrm{AUC}_{1} / \mathrm{AUC}_{2}$ ratio and $\mathrm{AUC}_{\text {stand. Significant differences were determined }}$ using Kruskal-Wallis tests and the Conover-Iman procedure $(\mathrm{p}<0.05)$ and highlighted with letters a to c.

Fig. 5: Simulated release kinetics using the model with the reference values of the parameters (Table 4): variation over time of aroma compound concentrations in (a) the air phase within the pharynx; (b) the mucosa layer in the pharynx; (c) saliva in the pharynx; (d) the air phase in the mouth; (e) the mucosa layer in the mouth; (f) saliva in the mouth; (g) the air phase in the nose; (h) the mucosa layer in the nose; and (i) the variation over time of saliva volume in the mouth. For each figure (except i), the insets focus on the first 3 seconds.

Fig. 6: Comparison between individual experimental and simulated release kinetics of: (a) ethyl propanoate ( $\mathrm{m} / \mathrm{z}$ 75); (b) (Z)-3-hexenol ( $\mathrm{m} / \mathrm{z}$ 83); and (c) 2-nonanone ( $\mathrm{m} / \mathrm{z} 143$ ) in the nasal cavity. Experimental release kinetics were obtained by PTR-MS measurements during 
the inhalation of gaseous sample by one panellist. d) Values of the parameters that were changed for model fitting (with respect to reference values). 


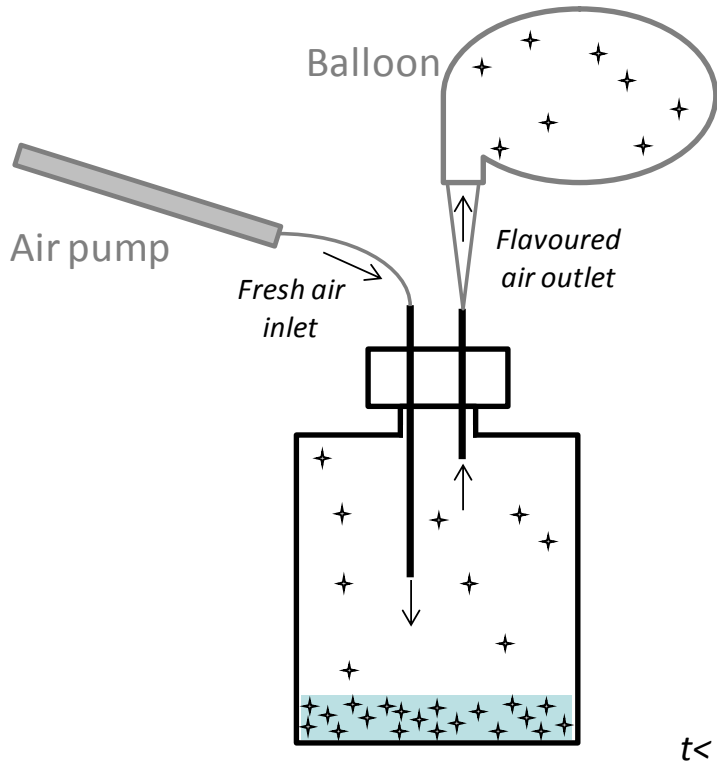

(1) Preparation

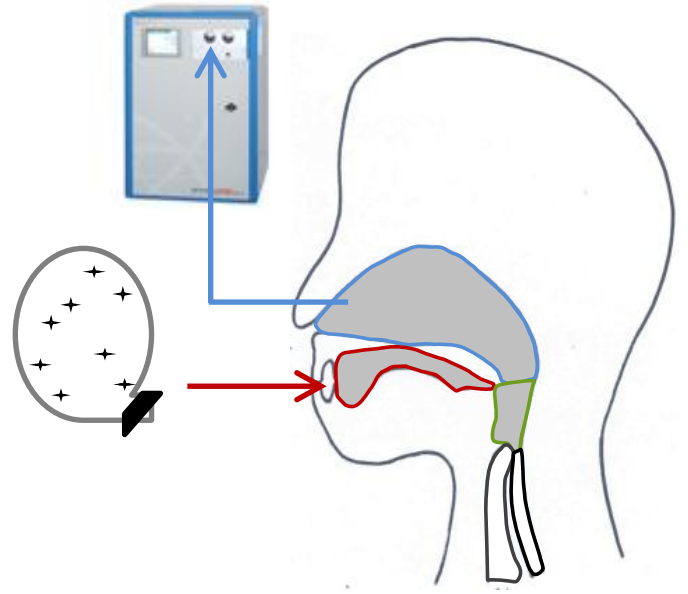

(2) Inhalation and measurement

Figure 1. Schematic representation of the experimental set-up for the preparation of gaseous samples with controlled volume. 


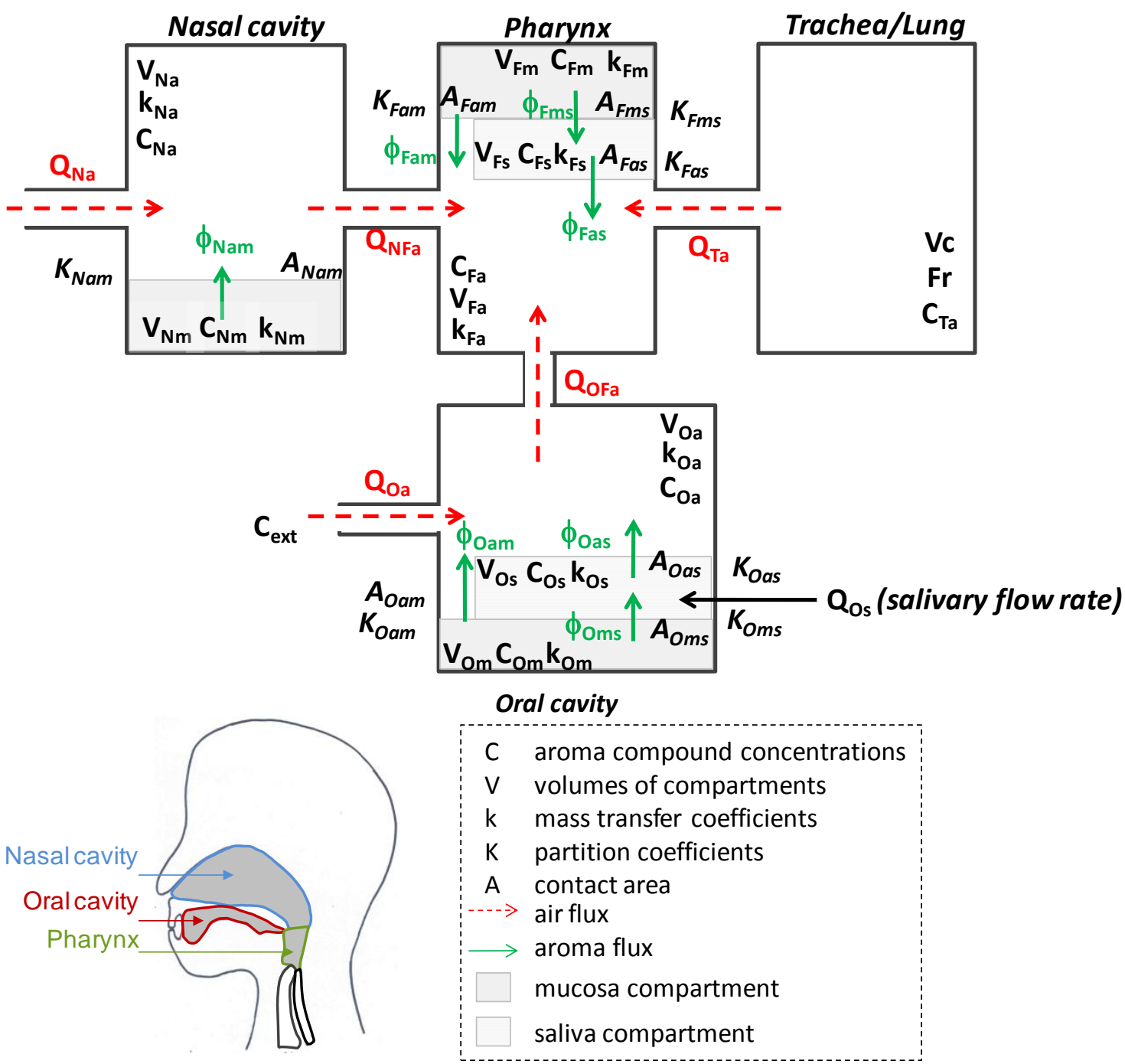

Figure 2. Schematic representation of the interconnected compartments of the naso-oropharyngeal cavities and the mechanisms involved in aroma release during the inhalation of gaseous samples. 


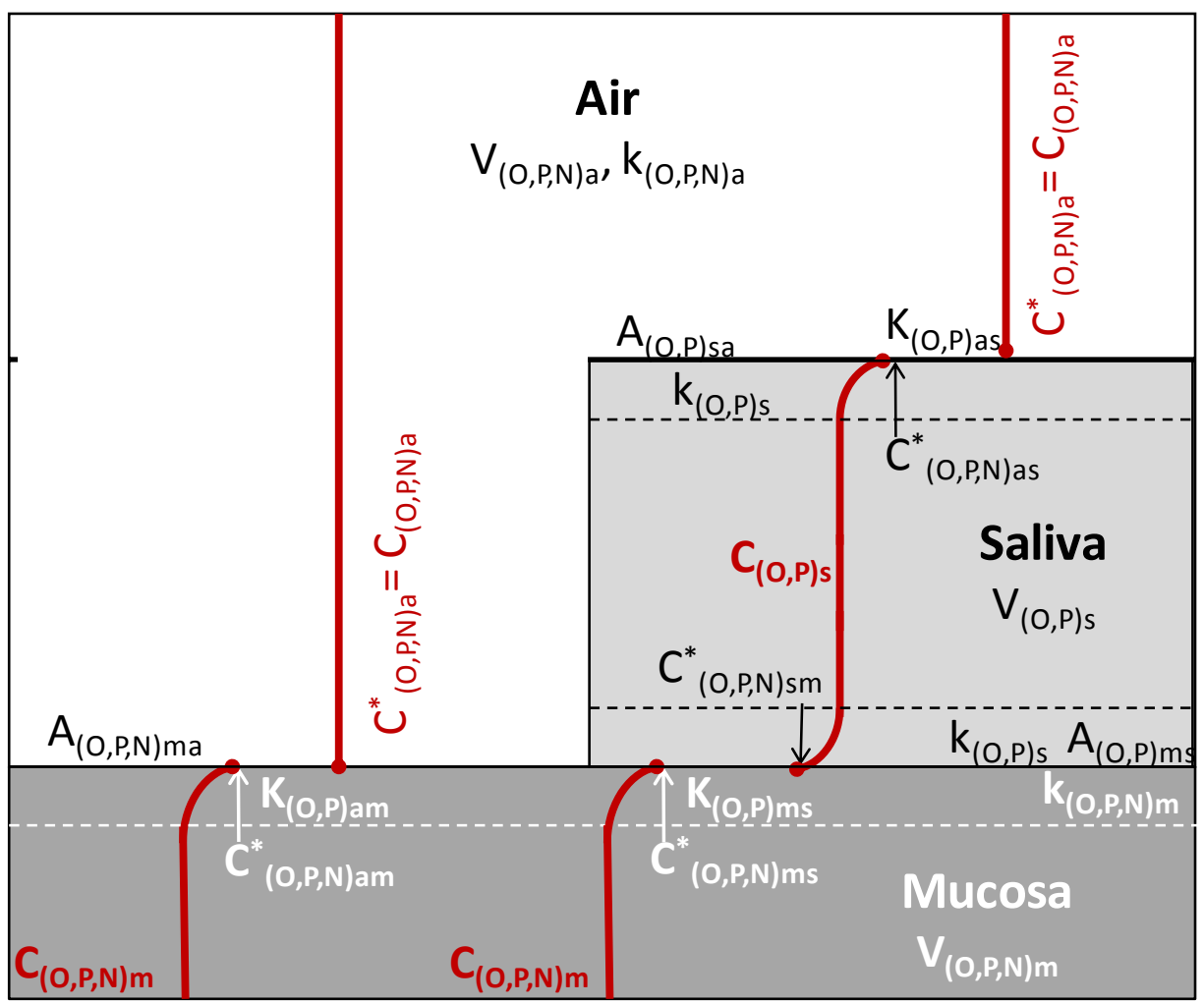

Figure 3. Schematic representation of the balances between the different compartments. Bold red lines represent concentration profiles and horizontal dotted lines represent the limits of boundary layers where mass transfer resistance was considered. 

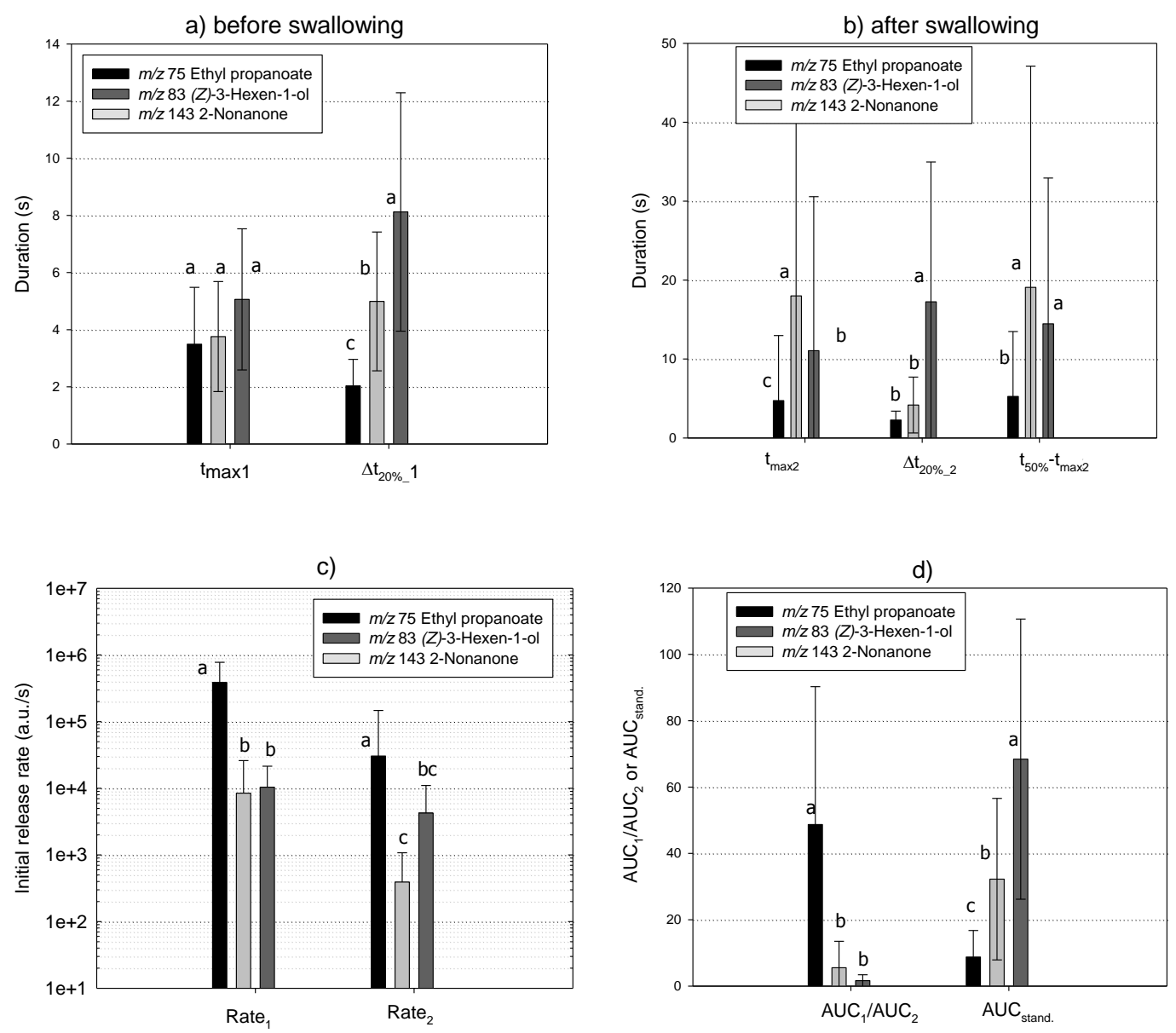

Figure 4. Comparison of parameters extracted from release kinetics that significantly differ between ions (means and associated standard deviations). (a) $t_{\max 1}$ and $\Delta t_{20 \% \_1}$, before swallowing; (b) $t_{\max 2}, \Delta t_{20 \% \_2}$ and $t_{50 \%}-t_{\max 2}$, after swallowing; (c) initial release rates Rate 1 and Rate ${ }_{2}$; (d) $\mathrm{AUC}_{1} / \mathrm{AUC}_{2}$ ratio and $\mathrm{AUC}_{\text {stand }}$. Significant differences were determined using Kruskal-Wallis tests and the Conover-Iman procedure $(\mathrm{p}<0.05)$ and highlighted with letters a to c. 

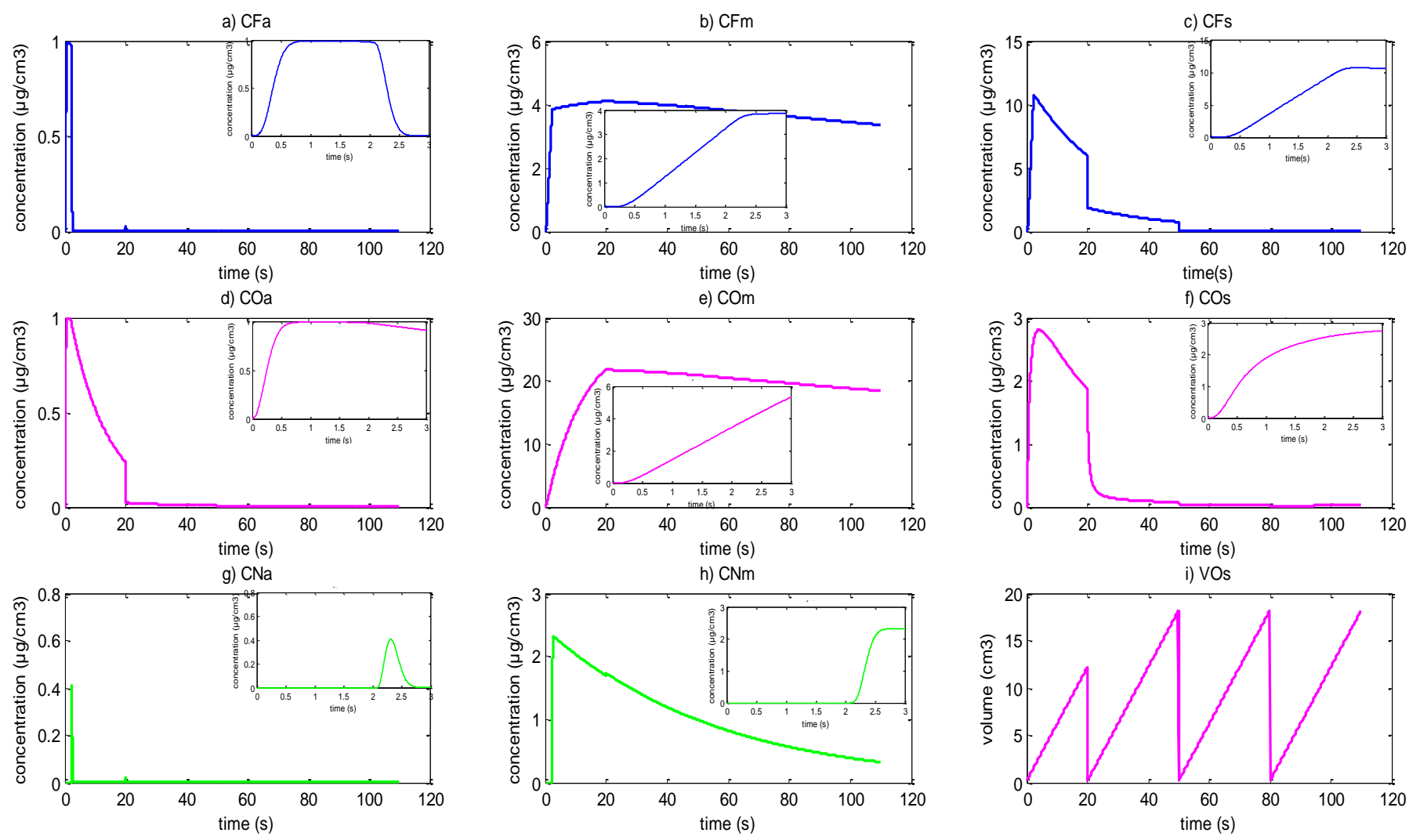

Figure 5. Simulated release kinetics using the model with the reference values of the parameters (Table 4): variation over time of aroma compound concentrations in (a) the air phase within the pharynx; (b) the mucosa layer in the pharynx; (c) saliva in the pharynx; (d) the air phase in the mouth; (e) the mucosa layer in the mouth; (f) saliva in the mouth; (g) the air phase in the nose; (h) the mucosa layer in the nose; and (i) the variation over time of saliva volume in the mouth. For each figure (except i), the insets focus on the first 3 seconds. 


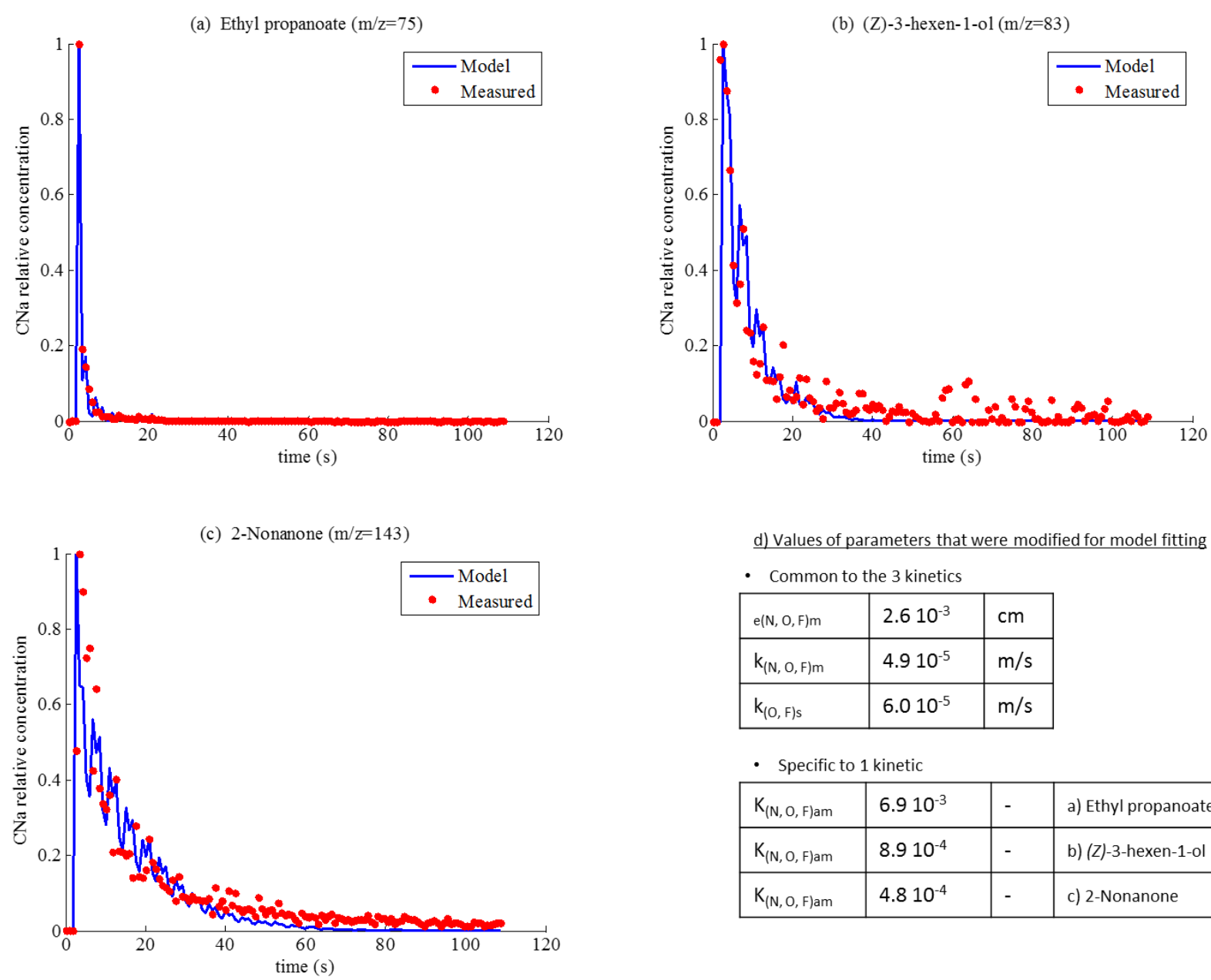

d) Values of parameters that were modified for model fitting - Common to the 3 kinetics

\begin{tabular}{|l|l|l|}
\hline$e(N, O, F) m$ & $2.610^{-3}$ & $\mathrm{~cm}$ \\
\hline $\mathrm{k}_{(\mathrm{N}, \mathrm{O}, \mathrm{F}) \mathrm{m}}$ & $4.910^{-5}$ & $\mathrm{~m} / \mathrm{s}$ \\
\hline $\mathrm{k}_{(\mathrm{O}, \mathrm{F}) \mathrm{s}}$ & $6.010^{-5}$ & $\mathrm{~m} / \mathrm{s}$ \\
\hline
\end{tabular}

- Specific to 1 kinetic
\begin{tabular}{|l|l|l|l|}
\hline $\mathrm{K}_{(\mathrm{N}, \mathrm{O}, \mathrm{F}) \mathrm{am}}$ & $6.910^{-3}$ & - & a) Ethyl propanoate \\
\hline $\mathrm{K}_{(\mathrm{N}, \mathrm{O}, \mathrm{F}) \mathrm{am}}$ & $8.910^{-4}$ & - & b) (Z)-3-hexen-1-ol \\
\hline $\mathrm{K}_{(\mathrm{N}, \mathrm{O}, \mathrm{F}) \mathrm{am}}$ & $4.810^{-4}$ & - & c) 2-Nonanone \\
\hline
\end{tabular}

Figure 6. Comparison between individual experimental and simulated release kinetics of: (a) ethyl propanoate ( $\mathrm{m} / \mathrm{z}$ 75); (b) (Z)-3-hexenol $(\mathrm{m} / \mathrm{z}$ 83); and (c) 2-nonanone $(\mathrm{m} / \mathrm{z}$ 143) in the nasal cavity. Experimental release kinetics were obtained by PTR-MS measurements during the inhalation of gaseous sample by one panellist using the NMS protocol. d) Values of the parameters that were changed for model fitting (with respect to reference values). 